\title{
Application of several activity coefficient models to water-organic-electrolyte aerosols of atmospheric interest
}

\author{
T. Raatikainen and A. Laaksonen \\ Department of Applied Physics, University of Kuopio, P.O. Box 1627, 70211 Kuopio, Finland
}

Received: 22 March 2005 - Published in Atmos. Chem. Phys. Discuss.: 2 June 2005

Revised: 17 August 2005 - Accepted: 7 September 2005 - Published: 22 September 2005

\begin{abstract}
In this work, existing and modified activity coefficient models are examined in order to assess their capabilities to describe the properties of aqueous solution droplets relevant in the atmosphere. Five different water-organicelectrolyte activity coefficient models were first selected from the literature. Only one of these models included organics and electrolytes which are common in atmospheric aerosol particles. In the other models, organic species were solvents such as alcohols, and important atmospheric ions like $\mathrm{NH}_{4}^{+}$could be missing. The predictions of these models were compared to experimental activity and solubility data in aqueous single electrolyte solutions with 31 different electrolytes.
\end{abstract}

Based on the deviations from experimental data and on the capabilities of the models, four predictive models were selected for fitting of new parameters for binary and ternary solutions of common atmospheric electrolytes and organics. New electrolytes $\left(\mathrm{H}^{+}, \mathrm{NH}_{4}^{+}, \mathrm{Na}^{+}, \mathrm{Cl}^{-}, \mathrm{NO}_{3}^{-}\right.$and $\mathrm{SO}_{4}^{2-}$ ) and organics (dicarboxylic and some hydroxy acids) were added and some modifications were made to the models if it was found useful. All new and most of the existing parameters were fitted to experimental single electrolyte data as well as data for aqueous organics and aqueous organicelectrolyte solutions. Unfortunately, there are very few data available for organic activities in binary solutions and for organic and electrolyte activities in aqueous organic-electrolyte solutions. This reduces model capabilities in predicting solubilities.

After the parameters were fitted, deviations from measurement data were calculated for all fitted models, and for different data types. These deviations and the calculated property values were compared with those from other non-electrolyte and organic-electrolyte models found in the literature. Finally, hygroscopic growth factors were calculated for four

Correspondence to: T. Raatikainen

(tomi.raatikainen@uku.fi)
$100 \mathrm{~nm}$ organic-electrolyte particles and these predictions were compared to experimental data and to predictions from other models.

All of the newly fitted models show good agreement with experimental water activity data in binary and ternary solutions. One of the models is for activities of non-electrolytes only, but the other three models show quite small deviations from measured electrolyte activities. Because there were not enough experimental data for organic and electrolyte activities, some models show bigger deviation for mutual deliquescence relative humidities of organic-electrolyte particles, but calculated growth factors for liquid droplets are quite close to the experimental data. Even in cases with somewhat bigger deviations, the results can be considered satisfactory, because they were calculated based mainly on the predictive properties of the models.

\section{Introduction}

Atmospheric aerosols have a cooling effect on the climate, but the magnitude of this effect is uncertain. Aerosol composition and size distribution are the most important properties that influence the magnitude of the cooling. Hygroscopic growth of aerosols and partitioning of volatile compounds between gas and particulate phases can be calculated with thermodynamic models in which non-ideal behaviour of liquid phase compounds are described with modelled activity coefficients. Most of the activity coefficient models used in aerosol modelling are suitable only for electrolyte solutions. However, atmospheric aerosols include both organic and inorganic components (Novakov and Penner, 1993; Saxena and Hildemann, 1996; Chow et al., 1994).

Water and electrolyte activities are calculated in most of the aerosol models, but the organic fraction is usually treated as an ideal solute or insoluble solid phase, or organics can be totally ignored. These are valid approximations in solutions

(C) 2005 Author(s). This work is licensed under a Creative Commons License. 
where the organic fraction is small. However, it has been estimated that up to $50 \%$ of aerosol dry mass is organic (Chow et al., 1994). Even if variations for the organic mass fractions are large, ignoring the organics can cause large deviations on calculated results. An activity coefficient model which is applicable for aqueous mixtures of organics and electrolytes is needed. The problem is that there are only a few activity coefficient models for organic-electrolyte mixtures (e.g. Ming and Russell, 2002). The two main reasons for this are lack of a reliable activity coefficient model for any kind of organicelectrolyte mixtures, and lack of experimental data for the atmospheric mixtures.

Because electrolytes and organics have different interactions in aqueous solutions, a large fraction of all activity coefficient models are applicable either for non-electrolyte solutions (e.g. Fredenslund et al., 1975; Abrams and Prausnitz, 1975) or for aqueous electrolyte solutions only (e.g. Clegg et al., 1998a; Pitzer, 1991). There are some methods for calculating activities in mixed solutions from binary solution data (e.g. Clegg et al., 2001; Topping et al., 2005). However, the results can be better if organic-electrolyte interactions are taken into account directly.

Most of the few organic-electrolyte models are designed for industrial purposes (e.g. Li et al., 1994), and the compounds in these models are usually different from the major species found in atmospheric aerosols. However, if a suitable model is found, new parameters can be fitted for the atmospheric compounds provided that experimental data is available.

Some activity coefficient models are designed for one purpose only (e.g. vapour-liquid equilibrium models). However, most organics and electrolytes form a solid phase at low relative humidities, and some of these compounds can also evaporate from aqueous droplets. For these reasons, the activity coefficient model should be applicable for water, organic and electrolyte activities in dilute and in saturated solutions.

Usually the inorganic fraction in atmospheric particles is composed of a few different ions (e.g. sulphates, nitrate, hydrogen and ammonium) whose chemical properties are well known. Several studies show that dicarboxylic acids are among the most common atmospheric organics, however, a number of other important species exist as well (Hemming and Seinfeld, 2001). Most of these organics have complex structures, and usually they are less studied than the inorganic compounds. Although there are some data sets available for the atmospheric organics, there are hardly any data for the mixtures of organics and electrolytes. However, there are predictive activity coefficient models that are based on the group contribution method, in which several similar compounds can be described with the same interaction parameters. Experimental data in parameter fitting can include only some compounds from one group, but the fitted parameters are applicable for the whole group. Then activities of the other compounds can be predicted. UNIFAC (Fredenslund et al., 1975) is one very popular predictive non-electrolyte activity coefficient model.

The first purpose of this study was to compare existing activity coefficient models that might be suitable for modelling of the hygroscopic properties of the atmospheric organicelectrolyte particles. The second purpose was to select some of these models to be extended for aqueous organicelectrolyte solutions of atmospheric interest by fitting new parameters. Because the experimental data needed for the fitting is very limited, we selected models that are predictive. The electrolytes in these models are composed of the ions $\mathrm{H}^{+}, \mathrm{NH}_{4}^{+}, \mathrm{Na}^{+}, \mathrm{Cl}^{-}, \mathrm{NO}_{3}^{-}$and $\mathrm{SO}_{4}^{2-}$. The organics selected for the parameter fitting are dicarboxylic acids (from oxalic to adipic acid) and acids including hydroxyl groups (citric, tartaric and malic acids). Because the fitted models are predictive, activities can be calculated for other similar multifunctional organic compounds.

\section{Thermodynamics}

In non-ideal solutions, activities (a) represent the effective concentrations which should be used instead of the real concentrations $(c)$. The relation between the effective and the real concentration is given by the activity coefficient $(\gamma)$ : $a=\gamma c$. Because there are different concentration scales, activities and activity coefficient depend on the concentration scale. A common unit for expressing electrolyte concentration is molality $m(\mathrm{~mol} / \mathrm{kg})$ i.e. number of electrolyte moles per one kilogram of solvent, where solvent can be defined as a single compound (e.g. water) or a solvent mixture (e.g. water-ethanol solution). The mole fraction $x$ is commonly used for non-electrolyte solutions.

It should be noted that organic compounds can, depending on the species, be considered either solvents or solutes. Some organics can, for example, dissolve electrolytes, whereas others are sparingly soluble in water. From the modelling viewpoint this is an important difference, as the standard state (at which thermodynamic potentials are compared) and the reference state (ideal solution limit) are usually different for solutes and solvents. In the following calculations, organics are considered as solvents.

The standard state is an ideal solution $(\gamma=1)$ with unit concentration at $298.15 \mathrm{~K}$. For solvents this is taken to be pure ideal solvent and for solutes ideal 1 molal aqueous solution. Pure water can be considered as an ideal solution, but usually 1 molal electrolyte solutions are not ideal, so this state is hypothetical. The selected organics are solids at room temperature, so also their standard states are hypothetical. The reference state for solvents is pure solvent and the reference state for electrolytes is infinitely dilute aqueous solution. One important constant for organic species is activity coefficient at infinite dilution $\left(\gamma^{\infty}\right)$. However, in this paper models are mainly for water activities, and infinite dilution activity coefficients are not considered. 
Water in a droplet is in equilibrium with ambient water vapour, when the vapour pressure at droplet surface equals the atmospheric partial pressure. For large droplets (larger than $100 \mathrm{~nm}$ in diameter), a good approximation is that the vapour pressure at droplet surface equals the saturation vapour pressure multiplied by water activity. By combining these considerations with the definition of relative humidity $(R H)$, we have $a_{w}=R H / 100 \%$. However, according to the Kelvin equation, the equilibrium vapour pressure over a curved surface is higher than that over a flat surface. The equilibrium relative humidity is now

$$
R H / 100 \%=a_{w} \exp \left(\frac{4 \sigma M_{w}}{R T \rho D_{p}}\right)
$$

where $\sigma(\mathrm{N} / \mathrm{m})$ is surface tension, $M_{w}(\mathrm{~kg} / \mathrm{mol})$ is molecular weight for water, $R=8.31451 \mathrm{~J} /(\mathrm{mol} \mathrm{K})$ is gas constant, $T$ $(\mathrm{K})$ is temperature, $\rho\left(\mathrm{kg} / \mathrm{m}^{3}\right)$ is solution density and $D_{p}(\mathrm{~m})$ is droplet diameter. Similarly, the vapour-liquid equilibrium (VLE) could be calculated for all volatile species including ammonia, some acids (e.g. $\mathrm{HCl}$ and $\mathrm{HNO}_{3}$ ) and some of the organics.

Most organic solvents are liquids at room temperature (e.g. ethanol), but in this study all pure organics are solids at room temperature. The melting temperatures (Table 1) can be much higher than the boiling point of water. Most electrolytes are also solids at room temperature with the exception of strong acids. For example, sulphuric acid does not have a solid phase at room temperature. Solid-liquid equilibrium (SLE) is strongly temperature dependent, and also here, solubilities are calculated as a function of temperature. The experimental solubility data used in this work falls in the temperature range $273.15-373.15 \mathrm{~K}$.

Salt solubilities can be calculated using solubility products $K_{s p}$, i.e. the product of cation (subscript $c$ ) and anion (subscript $a$ ) activities in the saturated solution.

$K_{s p}=\left(a_{c}^{\mathrm{sat}}\right)^{v+}\left(a_{a}^{\mathrm{sat}}\right)^{v-}$

where $v+$ and $v-$ are the stoichiometric numbers of cations and anions in the salt. The solubility product is a function of temperature, but usually tabulated $K_{s p}$ values are given at $298.15 \mathrm{~K}$. In addition to tabulated values, $K_{s p}$ can be calculated from the change of the Gibbs free energy using the free energies of formation $\Delta G_{f}(\mathrm{~J} / \mathrm{mol})$ for solid $\left(\Delta G_{f,(s)}\right)$ and dissolved salts $\left(\Delta G_{f,(a q)}=(\nu+) \Delta G_{f, c}+(\nu-) \Delta G_{f, a}\right)$ :

$K_{s p}(T)=\exp \left(\frac{\Delta G_{f,(s)}-\Delta G_{f,(a q)}}{R T}\right)$

These free energies of formation are tabulated at standard temperature $\left(T_{0}\right)$, usually $298.15 \mathrm{~K}\left(\Delta G_{f}^{0}\right)$. The temperature dependence of standard state chemical potentials can be calculated with an equation given by Ansari and Pandis (1999). With these standard state chemical potentials we can calculate the free energy change as a function of temperature. By
Table 1. Properties of the organic acids. Melting enthalpy $\Delta H_{m}$ $(\mathrm{kJ} / \mathrm{mol})$ and melting temperature $T_{m}(\mathrm{~K})$ for malonic acid are from Hansen and Beyer (2004), melting enthalpies were calculated for oxalic and citric acids, and for other organics these values are from NIST Chemistry webBook (http://webbook.nist.gov). Molecular weight $M(\mathrm{~g} / \mathrm{mol})$ and density $\rho\left(\mathrm{kg} / \mathrm{m}^{3}\right)$ for adipic acid are from Hori et al. (2003) and for other organics these are from Peng et al. (2001).

\begin{tabular}{llllll}
\hline Acid & Formula & $\Delta H_{m}$ & $T_{m}$ & $M$ & $\rho$ \\
\hline oxalic & $\mathrm{C}_{2} \mathrm{H}_{2} \mathrm{O}_{4}$ & 26.87 & 464.45 & 90.04 & 1900 \\
malonic & $\mathrm{C}_{3} \mathrm{H}_{4} \mathrm{O}_{4}$ & 24.94 & 407.46 & 104.06 & 1630 \\
succinic & $\mathrm{C}_{4} \mathrm{H}_{6} \mathrm{O}_{4}$ & 33.12 & 457.0 & 118.09 & 1552 \\
glutaric & $\mathrm{C}_{5} \mathrm{H}_{8} \mathrm{O}_{4}$ & 23.36 & 371.0 & 132.12 & 1429 \\
adipic & $\mathrm{C}_{6} \mathrm{H}_{10} \mathrm{O}_{4}$ & 34.85 & 426.4 & 146.14 & 1360 \\
citric & $\mathrm{C}_{6} \mathrm{H}_{8} \mathrm{O}_{7}$ & 37.52 & 427.15 & 192.12 & 1665 \\
tartaric & $\mathrm{C}_{4} \mathrm{H}_{6} \mathrm{O}_{6}$ & 32.30 & 445.1 & 150.09 & 1759.8 \\
malic & $\mathrm{C}_{4} \mathrm{H}_{6} \mathrm{O}_{5}$ & 33.52 & 402.0 & 134.09 & 1609 \\
\hline
\end{tabular}

combining Eq. (3) and the equation for the temperature dependence of the free energy change, we obtain an equation for the temperature dependence of solubility products

$$
\begin{aligned}
K_{s p}(T)= & K_{s p}\left(T_{0}\right) \exp \left[\frac{H_{f,(s)}^{0}-H_{f,(a q)}^{0}}{R}\left(\frac{1}{T}-\frac{1}{T_{0}}\right)+\right. \\
& \left.\frac{C_{(s)}-C_{(a q)}}{R}\left(\ln \left(\frac{T_{0}}{T}\right)-\frac{T_{0}}{T}+1\right)\right]
\end{aligned}
$$

where $H_{f,(s)}^{0}$ and $H_{f,(a q)}^{0}(\mathrm{~J} / \mathrm{mol})$ are the enthalpies of formation of solid salt and aqueous ions at $298.15 \mathrm{~K}$, respectively, and $C_{(s)}$ and $C_{(a q)}(\mathrm{J} /(\mathrm{mol} \mathrm{K}))$ are the heat capacities for solid salt and aqueous ions, respectively. Solubility products at $298.15 \mathrm{~K}\left(K_{s p}\left(T_{0}\right)\right)$ for the six salts modelled in the fitted models are from Clegg et al. (1998b) and the other thermodynamic constants are from Weast (1987) and Ansari and Pandis (1999). If the solubility products at $298.15 \mathrm{~K}$ were not available (comparison of existing models), these were calculated from the standard state Gibbs free energies of formation with Eq. (3).

There are no solubility products available for organics, but saturation activities ( $\left.a_{o}^{\text {sat }}\right)$ can be approximated using the enthalpy of melting $\Delta H_{m}(\mathrm{~J} / \mathrm{mol})$ and melting temperature $T_{m}$ (K)

$\ln a_{o}^{\mathrm{sat}}=\frac{\Delta H_{m}}{R}\left(\frac{1}{T_{m}}-\frac{1}{T}\right)$

Because melting enthalpy is a function of temperature, this equation is more accurate if the temperature $T$ is close to the melting temperature. However, most of the melting temperatures are higher than $400 \mathrm{~K}$. There were no reliable melting enthalpies available for oxalic and citric acids so these values were calculated based on thermodynamic data from the NIST 
Chemistry webBook (http://webbook.nist.gov) and Knovel database (http://www.knovel.com/knovel2/default.jsp). Because these values may be inaccurate, the solubilities of oxalic and citric acids were not used in the fitting process. However, the solubilities were included in the comparisons of the fitted models. Enthalpies of phase transitions between different crystalline forms were included in the melting enthalpies if these values were available. Melting enthalpies and melting temperatures for the modelled organics are given in the Table 1.

\subsection{Growth factors for organic-salt particles}

Hygroscopic growth factors ( $G F$, aqueous droplet diameter divided by dry particle diameter) can be calculated for originally dry particles (known size and organic-salt mass ratio) as a function of ambient relative humidity by solving the liquid phase equilibrium concentrations. Pure component densities and molecular weights, which are needed in solving mole numbers from dry particle volume and organic-salt mass ratio, are given in the Table 1 for organics. The corresponding electrolyte parameters can be found from Weast (1987).

Droplet volume is proportional to the cube of the diameter, and thus the growth factor can be calculated from dry and wet particle volumes. We can calculate the dry volume from the given dry diameter, but direct calculation of the liquid phase volume is difficult without solution density data. For simplicity, we approximated the liquid droplet volume as sum of the dry volume and the volume of condensed water.

The equilibrium liquid phase concentrations can be calculated by solving the water concentration so that the Kelvin equation (Eq. 1) is satisfied. At the same time organic and salt concentrations in the liquid phase must be less than or equal to their saturation concentrations. If there is a solid phase, the corresponding liquid phase compound must be saturated. The solid-liquid equilibrium is found by transferring organic compound and salt between the liquid and the solid phases while maintaining the total concentration the same as in the original dry particle.

If a solid phase exists, there exists a single relative humidity at which both the organic compound and the salt are saturated. This relative humidity, called mutual deliquescence relative humidity (MDRH), is the minimum relative humidity where the liquid phase exists. Only supersaturated solutions can exist below the MDRH. Also, there can be a relative humidity at which the solid phase dissolves completely. After this $R H$ the solid phase is not possible, and the equilibrium water concentration is calculated by solving Eq. (1) only.

Solution density and surface tension are needed in Eq. (1), but these are rarely available for multicomponent mixtures. For simplicity, we decided to use the surface tension $(0.072 \mathrm{~N} / \mathrm{m})$ and the density of pure water $\left(997.1 \mathrm{~kg} / \mathrm{m}^{3}\right)$. Growth factors were calculated for particles with dry diameter of $100 \mathrm{~nm}$, so the Kelvin term has only a small effect to the equilibrium vapour pressure.

\section{Comparison of published activity coefficient models}

Five different activity coefficient models were selected from the literature. All models are suitable for water-organicelectrolyte mixtures. However, in four of these models the organic species are alcohols and other organic solvents which are not common in atmospheric aerosols. Moreover, some of the important atmospheric ions (e.g. $\mathrm{H}^{+}$and $\mathrm{NH}_{4}^{+}$) are missing from most of the models. Only the fifth model is fitted for organic-electrolyte mixtures relevant in the atmosphere, however, parameters are available for a few ternary mixtures only.

Some of the selected models have a commonly used name, but not all. Here, the models are called LIQUAC (Li et al., 1994), LIFAC (Yan et al., 1999), Extended UNIQUAC (Thomsen et al., 1996), Modified UNIFAC (Achard et al., 1994) and Ming and Russell model (Ming and Russell, 2002), which is the only model fitted for atmospheric mixtures.

These models are combinations of different parts, usually an electrolyte part, a non-electrolyte part and an additional mixture part. LIQUAC has three parts, where the electrolyte part is based on the Debye-Hückel theory (Fowler and Guggenheim, 1949), the non-electrolyte part is UNIQUAC (Abrams and Prausnitz, 1975) and the third part is virial equation for solvent-ion interactions. LIFAC is similar to LIQUAC except that all species are described with functional groups. For this reason the non-electrolyte part is UNIFAC (Fredenslund et al., 1975) instead of UNIQUAC. Extended UNIQUAC is a combination of UNIQUAC as nonelectrolyte part and an electrolyte part based on DebyeHückel theory. Modified UNIFAC has Larsen's UNIFAC (Larsen et al., 1987) as non-electrolyte part and a DebyeHückel theory based electrolyte part. Ming and Russell model is a combination of UNIFAC as non-electrolyte part and the Clegg et al. (1992) electrolyte model. In fact, Ming and Russell model reduces to the Clegg model in aqueous electrolyte solutions.

All necessary parameters for LIQUAC, LIFAC and Modified UNIFAC have been published in the original articles. Parameters for Extended UNIQUAC are published in Thomsen et al. (1996); Iliuta et al. (2000); Thomsen and Rasmussen (1999). Parameters for the non-electrolyte part of the Ming and Russell model are given in the original article. The electrolyte part, i.e. the Clegg model, has temperature dependent parameters for four ions corresponding to four single electrolyte solutions (Clegg et al., 1998a). However, because parameters for most of the electrolytes are available only at constant temperature $(298.15 \mathrm{~K})$, we decided to use these constant temperature parameters for all electrolytes. The model parameters are from Clegg et al. (1992, 1998b).

Some of the models have limitations, such as vapourliquid equilibrium only, room temperature only, maximum electrolyte molality, etc., but in the model comparison these limitations are ignored. However, electrolyte molalities were 
Table 2. Sources for experimental single electrolyte data. Water activity data for $\mathrm{HNO}_{3}$ was generated from fitting of Clegg and Brimblecombe (1990). Water activities for electrolytes from Hamer and Wu (1972) were calculated from osmotic coefficients.

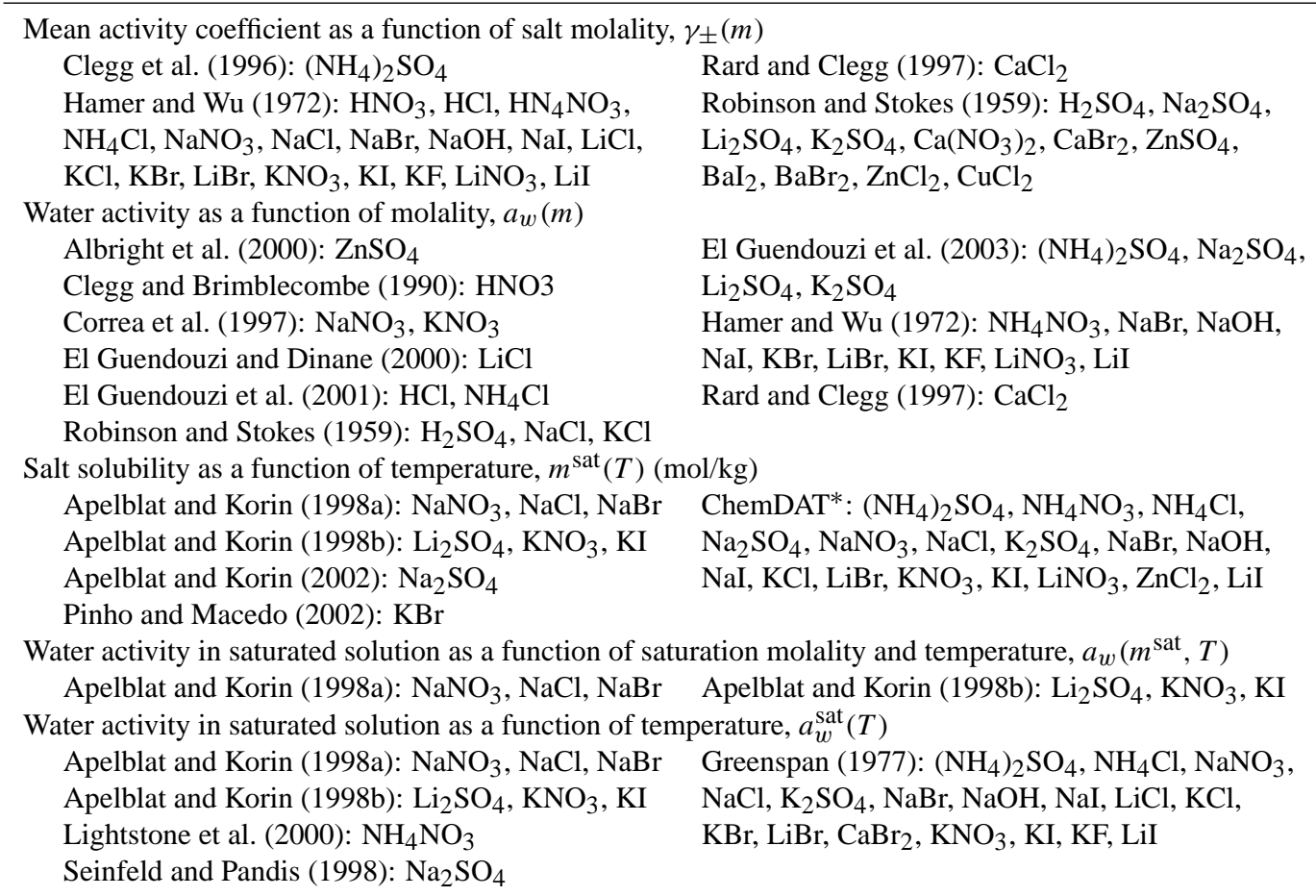

*ChemDAT - The Merck Chemical Databases (http://chemdat.merck.de/mda/int_en/labtool/index.html)

limited to $30 \mathrm{~mol} / \mathrm{kg}$, because some models had difficulties at very high electrolyte molalities. This same limitation was used in parameter fitting (Sect. 4.3). Although most of the published models are for vapour-liquid equilibrium, equations were usually given for electrolyte activities. Some of these models include values that are functions of temperature (e.g. water density, dielectric constant), but here these are considered constant. This approximation has very small effect to the calculated activity coefficients.

Most electrolytes dissociate completely, but one exception is sulphuric acid $\left(\mathrm{H}_{2} \mathrm{SO}_{4}\right)$, for which the second dissociation $\left(\mathrm{HSO}_{4}^{-} \rightleftharpoons \mathrm{H}^{+}+\mathrm{SO}_{4}^{2-}\right)$ is not complete. The equilibrium could be calculated, but this is done only in the Ming and Russell (Clegg) model. In the other models, sulphuric acid is taken to dissociate completely into two $\mathrm{H}^{+}$and one $\mathrm{SO}_{4}^{2-}$ ions.

\subsection{Experimental single electrolyte data}

The only common solvent for the five models is water and for this reason, the models were tested only for aqueous single electrolyte solutions. Because there are only few electrolyte solutions for which all models are applicable, a large number of electrolytes was selected for the model comparison. The 31 electrolytes are $\mathrm{H}_{2} \mathrm{SO}_{4}, \mathrm{HNO}_{3}, \mathrm{HCl},\left(\mathrm{NH}_{4}\right)_{2} \mathrm{SO}_{4}$, $\mathrm{NH}_{4} \mathrm{NO}_{3}, \mathrm{NH}_{4} \mathrm{Cl}, \mathrm{Na}_{2} \mathrm{SO}_{4}, \mathrm{NaNO}_{3}, \mathrm{NaCl}, \mathrm{Li}_{2} \mathrm{SO}_{4}, \mathrm{~K}_{2} \mathrm{SO}_{4}$,
$\mathrm{NaBr}, \mathrm{NaOH}, \mathrm{NaI}, \mathrm{LiCl}, \mathrm{KCl}, \mathrm{CaCl}_{2}, \mathrm{Ca}\left(\mathrm{NO}_{3}\right)_{2}, \mathrm{KBr}, \mathrm{LiBr}$, $\mathrm{CaBr}_{2}, \mathrm{ZnSO}_{4}, \mathrm{KNO}_{3}, \mathrm{BaI}_{2}, \mathrm{BaBr}_{2}, \mathrm{KI}, \mathrm{KF}, \mathrm{LiNO}_{3}, \mathrm{ZnCl}_{2}$, $\mathrm{CuCl}_{2}$ and $\mathrm{LiI}$.

Experimental single electrolyte data is categorized into five different data types. Each data type includes at least six but not more than 31 experimental data sets for single electrolytes. Data types and data sources for each electrolyte are presented in Table 2.

Mean activity coefficient and water activity data is given at constant temperature, which is usually $298.15 \mathrm{~K}$, but there are some data sets measured at $293.15 \mathrm{~K}$ and $303.15 \mathrm{~K}$. Electrolyte molalities depend on the data set, but usually the molalities range from zero to saturation molality. Solubility and water saturation activity data is given as a function of temperature. Temperatures, as well as solubilities, depend on the data set, but the minimum temperature is $273.15 \mathrm{~K}$ and the maximum temperature is $373.15 \mathrm{~K}$.

\subsection{Deviations from experimental data}

Model deviations were calculated for each of the five data types. Model deviation for one data type is calculated as average of the deviations of its data sets. The deviation for one data set is the average absolute difference between model predictions and experimental data. Because these models are suitable for different mixtures, the number of included data 
Table 3. Experimental single electrolyte data types, number of data sets $(\mathrm{N})$ and deviations for each published activity coefficient model. The unit for deviations in solubility data $\left(m^{\text {sat }}(T)\right)$ is $\mathrm{mol} / \mathrm{kg}$.

\begin{tabular}{|c|c|c|c|c|c|c|c|c|c|c|}
\hline \multirow[b]{2}{*}{ Data type } & \multicolumn{2}{|c|}{ LIQUAC } & \multicolumn{2}{|r|}{ LIFAC } & \multicolumn{2}{|c|}{ Ext. UNIQUAC } & \multicolumn{2}{|c|}{ Mod. UNIFAC } & \multicolumn{2}{|c|}{ Ming and Russell } \\
\hline & $\mathrm{N}$ & deviation & $\mathrm{N}$ & deviation & $\mathrm{N}$ & deviation & $\mathrm{N}$ & deviation & $\mathrm{N}$ & deviation \\
\hline$\gamma_{ \pm}(m)$ & 26 & 0.3884 & 15 & 0.5768 & 13 & 0.5827 & 15 & 1.281 & 12 & 1.373 \\
\hline$a_{w}(m)$ & 20 & 0.001941 & 12 & 0.005822 & 13 & 0.01162 & 16 & 0.02283 & 11 & 0.002188 \\
\hline$m^{\mathrm{sat}}(T)$ & 12 & 7.369 & 9 & 4.498 & 9 & 3.758 & 12 & 5.089 & 7 & 0.8100 \\
\hline$a_{w}\left(m^{\mathrm{sat}}, T\right)$ & 5 & 0.06602 & 5 & 0.09132 & 3 & 0.01689 & 5 & 0.08204 & 2 & 0.01801 \\
\hline$a_{w}^{\mathrm{sat}}(T)$ & 14 & 0.05173 & 8 & 0.04705 & 9 & 0.02077 & 15 & 0.04780 & 8 & 0.01181 \\
\hline
\end{tabular}

sets is given for each model and data type. Results of the model comparisons are given in Table 3 .

When deviations were calculated for the Modified UNIFAC, it was found that there are three mean activity coefficient data sets for which the average absolute deviation is more than 100. It was considered that the Modified UNIFAC is not suitable for these mixtures so these three average absolute deviations were not included in the model deviation.

Modified UNIFAC uses hydrated mole fractions, meaning that some fraction of the liquid water is assumed to be incorporated in hydrates. For this reason, it is possible that all water will be in hydrates at high electrolyte molalities resulting in zero water mole fraction whereby activity coefficients can not be calculated. This characteristic makes it difficult to use the model for very soluble electrolytes (e.g. sulphuric acid). However, this model includes a large number of different electrolytes, and most of these are not extremely soluble.

LIQUAC and Ming and Russell model both show the smallest deviations for two data types and Extended UNIQUAC for one data type. On the other hand, LIQUAC shows the biggest deviation for two data types, and Ming and Russell model, Modified UNIFAC and LIFAC each for one data type. LIQUAC has parameters for most of the 31 electrolytes, whereas the other models have parameters for less than a half of the electrolytes. It should be noted that even if the number of applicable data sets for two models are equal, one of them may include solutions that are more difficult to fit, leading to larger average deviations even though the model in itself is not worse than the other.

\section{Models selected for fitting parameters for atmo- spheric organic-electrolyte-water mixtures}

Only one of the five models considered above has parameters for common atmospheric organics. The Ming and Russell model has parameters for e.g. dicarboxylic and hydroxy acids, but parameters are available only for four electrolytes. The organics described in the other four models are mainly organic solvents, such as alcohols, but these are not common in the atmosphere. Furthermore, some of the most common atmospheric ions are not included these models. For this rea- son, we decided to select models for fitting of new parameters for common atmospheric mixtures of organics and electrolytes.

When selecting models for fitting, not only deviations in water-electrolyte mixtures, but also the suitability of the model for water-organic-electrolyte solutions and organicwater solutions need to be considered. Also, the number of fitting parameters and need for experimental data, have great influence to the fitting. A selected model should be suitable for calculating both solvent and solute activities, and for solubility and vapour-liquid equilibrium calculations. All of the previous models should be suitable for organic-water and ternary solutions, but some principal differences exist. The biggest difference is that LIFAC, Modified UNIFAC and Ming and Russell models are based on the group contribution method, and thus are predictive, whereas LIQUAC and Extended UNIQUAC are not predictive. Because the lack of experimental organic-electrolyte data for common atmospheric mixtures is the biggest problem in parameter fitting, we decided to select only predictive models for the fitting procedure.

4.1 Electrolytes and organic species selected for parameter fitting

$\mathrm{Na}^{+}, \mathrm{H}^{+}, \mathrm{NH}_{4}^{+}, \mathrm{NO}_{3}^{-}, \mathrm{Cl}^{-}$and $\mathrm{SO}_{4}^{2-}$ are common atmospheric ions, and these ions were also selected for the parameter fitting. Because the models should be predictive, it is assumed that all electrolytes dissociate completely into ions, and the activities can then be calculated for each liquid phase ion. This means that ions are considered as functional groups which are not parts of other compounds, just like UNIFAC groups water $\left(\mathrm{H}_{2} \mathrm{O}\right)$ and methanol $\left(\mathrm{CH}_{3} \mathrm{OH}\right)$.

The organic fraction of atmospheric particles can be composed of several different organics, but organics with more than one polar functional group are very common. For this study, we selected organics which have at least two acid groups $(\mathrm{COOH})$ and they may have hydroxyl groups $(\mathrm{OH})$. Experimental data for fitting were available for dicarboxylic acids (oxalic, malonic, succinic, glutaric and adipic acid) and for citric, tartaric and malic acids which have both acid and 
hydroxyl groups. These non-electrolytes can be described with the functional groups $\mathrm{H}_{2} \mathrm{O}, \mathrm{CH}_{\mathrm{n}}, \mathrm{OH}$ and $\mathrm{COOH}$.

\subsection{The selected models}

After considering deviations of model output from experimental data as well as the predictive capabilities of the models, we selected four models for fitting of new parameters. Here we outline the main features of the selected models briefly; detailed model equations and parameters are given in appendices. Two of the selected models are nearly the same as in the model comparison above, one model is a combination of two models considered above, and one model is actually the non-electrolyte part of two of the models included in the model comparison. Because the model equations have already been published elsewhere, we are not going to examine the theory of the selected models, but refer instead to the original articles. However, we will examine the model accuracies, predictive capabilities and suitability for different calculations for atmospheric organic-electrolyte mixtures.

\subsubsection{UNIFAC}

The first model selected for fitting is the original UNIFAC (Fredenslund et al., 1975). New functional groups were added to the model for the selected ions. Because UNIFAC is a non-electrolyte model, it was not included in the model comparison in Sect. 3. However, UNIFAC is used as one component in many organic-electrolyte models, for example in LIFAC, Ming and Russell model and Modified UNIFAC, which uses slightly different Larsen's UNIFAC (Larsen et al., 1987). In these models UNIFAC has the biggest effect to the activities of non-electrolytes, and other terms have control over ion activities. Therefore, our model is not suitable for calculation of ion activities even if new parameters are fitted. However, this model is applied for calculating activities of organic species and water in both non-electrolyte and electrolyte solutions. From now on the term UNIFAC refers to our fitted UNIFAC, and when other UNIFAC models (e.g. the original UNIFAC) are used, it is stated in their names. The model equations and parameters are given in Appendix A.

\subsubsection{LIFAC}

Unlike LIQUAC (Li et al., 1994), LIFAC (Yan et al., 1999) is based on the group contribution method, and for this reason the second model selected for fitting is LIFAC. Model equations remain unaltered, but functional groups were added for the new organics and ions. LIFAC is a combination of a simple electrolyte model, original UNIFAC, and a term for non-electrolyte-ion interactions. The simple electrolyte model has no mixture parameters, but only pure component properties (e.g. density). LIFAC reduces to UNIFAC in nonelectrolyte solutions, but all three parts are included in aqueous electrolyte solutions. The model equations and parame- ters are given in Appendix B. From now on the term LIFAC refers to our fitted LIFAC instead of the original model.

\subsubsection{Ming and Russell}

Ming and Russell (2002) model has parameters for mixtures of electrolytes and organics with several functional groups, and this model was selected as the third model for parameter fitting. Compared to the original model, one normalization term was dropped, and again functional groups were added for the new organics and ions. The reason for ignoring the normalization term is explained in Appendix C. This model is a combination of Clegg et al. (1992) electrolyte model and the original UNIFAC. The new model reduces to UNIFAC in non-electrolyte solutions, and to the Clegg et al. (1992) model in aqueous electrolyte solutions. The model equations and parameters are given in Appendix C. The original Ming and Russell (Clegg) model was the only model in the comparison of the published models in which the equilibrium for the incomplete dissociation of $\mathrm{HSO}_{4}^{-}$ion was calculated, and this is done in the new model also. In addition to the selected ions, $\mathrm{HSO}_{4}^{-}$ion was added to the model. In the other selected models, $\mathrm{HSO}_{4}^{-}$ion is expected to dissociate into $\mathrm{H}^{+}$ and $\mathrm{SO}_{4}^{2-}$ ions. From now on the term Ming and Russell model refers to our fitted model instead of the original one. When the original model is used, it is called the original Ming and Russell model.

\subsubsection{Extended UNIFAC}

The fourth model is a combination of Extended UNIQUAC (Thomsen et al., 1996) and Modified UNIFAC (Achard et al., 1994). Extended UNIQUAC is a combination of a simple electrolyte model and UNIQUAC (Abrams and Prausnitz, 1975) for non-electrolytes, but the UNIQUAC part makes this model non-predictive. Modified UNIFAC is a combination of a simple electrolyte model and Larsen's UNIFAC (Larsen et al., 1987), but the use of the hydrated mole fractions reduces model capabilities for concentrated electrolyte solutions. By combining the electrolyte part of Extended UNIQUAC version of Iliuta et al. (2000) and the original UNIFAC, we have our new model. From now on, this new model is called Extended UNIFAC. Again, new groups for the selected organics and ions were added to the model. This model reduces to UNIFAC in non-electrolyte solutions. The model equations and parameters are given in Appendix D.

\subsection{Parameter fitting}

Because all new models reduces to UNIFAC in nonelectrolyte solutions, we can use the same organic-water UNIFAC parameters. The original UNIFAC (Fredenslund et al., 1975) is quite accurate for simple organics like alcohols, but if one compound has two closely-spaced polar groups, the intramolecular interactions may cause large 
Table 4. Sources for experimental non-electrolyte and organic-electrolyte data used in the parameter fitting and model comparison. In addition to data where solubilities of oxalic and citric acids are needed, mixtures marked with asterisks were not used in the parameter fitting.

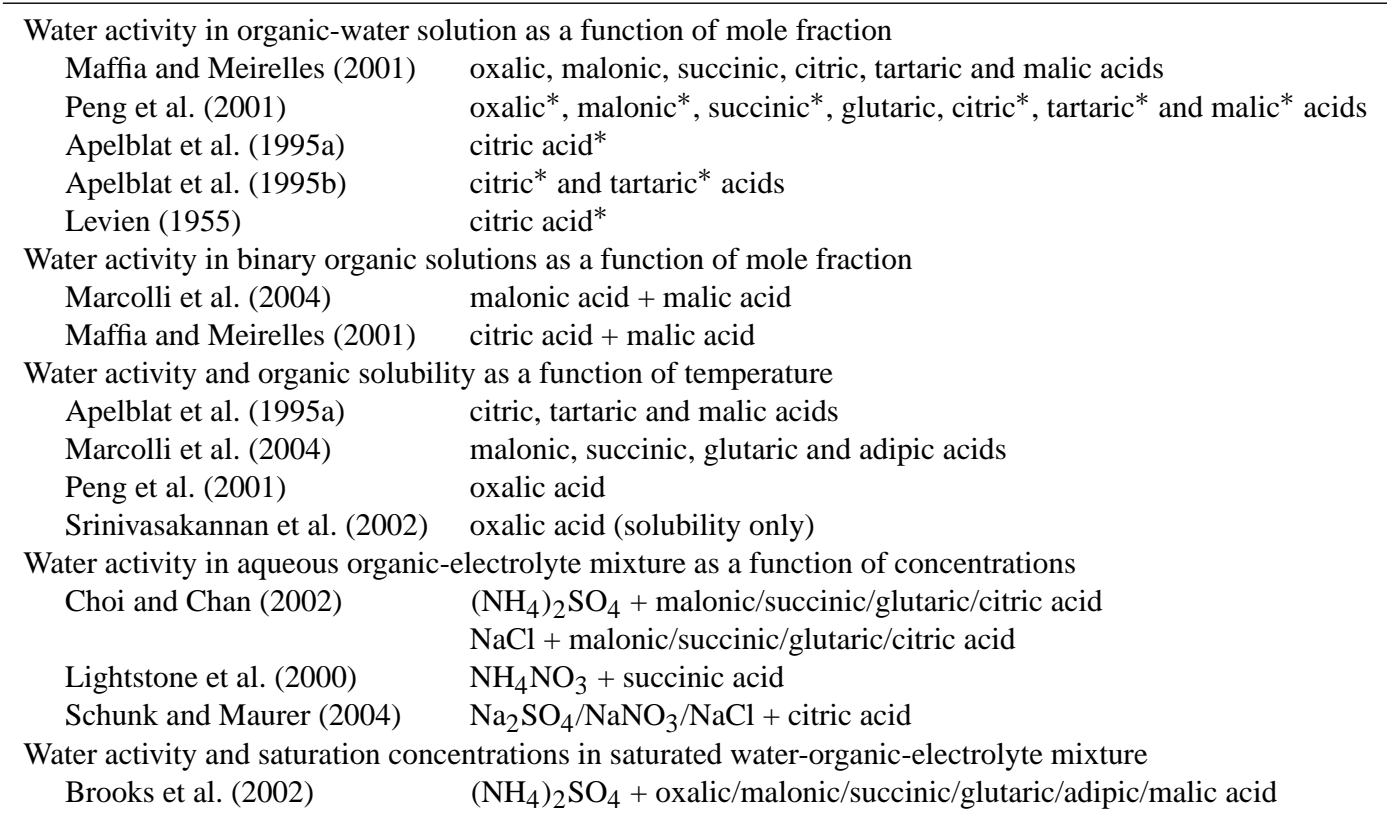

errors to the calculated activity coefficients. Improved results are obtained if new UNIFAC parameters are added or existing parameters are refitted for such compounds. Because the selected organics have at least two polar groups in relatively short carbon chain, we decided to refit all UNIFAC interaction parameters. However, pure component parameters for the solvent groups (surface and area parameters) are same as in the original UNIFAC.

The models treat electrolyte solutions differently, so the rest of the mixture parameters were fitted separately for each model using electrolyte-water and organic-electrolyte-water data. Most of the mixture parameters were fitted, but in addition to the non-electrolyte parameters, some of the interaction parameters were kept constant because of model considerations (e.g. UNIFAC interaction parameters for ions are zeros in LIFAC and Clegg et al. (1992) model parameters in the electrolyte part of the Ming and Russell model were not fitted). Furthermore, surface and area parameters for the ions were given constant values.

Model parameters were obtained by minimizing the sum of squared relative deviations of every data sets with the Nelder-Mead method (Nelder and Mead, 1965). The fitted non-electrolyte parameters, which are common for all new models, are presented in Appendix A and the remaining model-specific parameters are presented in Appendices A-D for each model.

\subsubsection{Experimental data}

Experimental mixed electrolyte data can be found in the literature, however, we limit ourselves to considering single electrolytes. The single electrolyte data for $\mathrm{NaNO}_{3}$, $\mathrm{NaCl}, \mathrm{Na}_{2} \mathrm{SO}_{4}, \mathrm{HNO}_{3}, \mathrm{HCl}, \mathrm{H}_{2} \mathrm{SO}_{4}, \mathrm{NH}_{4} \mathrm{NO}_{3}, \mathrm{NH}_{4} \mathrm{Cl}$ and $\left(\mathrm{NH}_{4}\right)_{2} \mathrm{SO}_{4}$, corresponding to the selected six ions, are the same as in the Table 2 except that water saturation activity data $\left(a_{w}^{\text {sat }}(T)\right)$, which requires calculation of electrolyte solubility, was not included in the fitting. Instead of electrolyte solubility calculations during the minimization, we compared solubility products and products of ion activities calculated at given saturation molalities. Because our UNIFAC is for activity coefficients of non-electrolytes, electrolyte mean activity coefficient and salt solubility data were not used in the parameter fitting.

Sources and mixtures for non-electrolyte and organicelectrolyte data are given in Table 4. The non-electrolyte data in fitting includes water activities in aqueous single and binary organic solutions as a function of mole fractions at $298.15 \mathrm{~K}$. The solubility and water activity data were used twice. In the first place, water and organic activities were calculated at given saturation concentration and temperature. The calculated water activities were then compared with experimental water activities, and organic activities were compared with those calculated from melting enthalpies. Because the melting enthalpies of oxalic and citric acids may be inaccurate, solubilities of these organics were not included in the fitting. However, these compounds were 
Table 5. Experimental non-electrolyte data types, number of mixtures (N) and deviations for our fitted UNIFAC and three other UNIFAC models. In addition to experimental data in the Table 4, data from Apelblat et al. (1995a,b); Levien (1955); Srinivasakannan et al. (2002) was included.

\begin{tabular}{llllll}
\hline Data type & $\mathrm{N}$ & refitted UNIFAC & orig. Ming and Russell & orig. UNIFAC & Peng et al. (2001) \\
\hline$a_{w}\left(x_{o}\right)$ & 7 & 0.02918 & 0.06483 & 0.07775 & 0.02265 \\
$x_{o}^{\text {sat }}(T)$ & 8 & 0.01618 & 0.06994 & 0.08314 & 0.03060 \\
$a_{w}\left(x_{o}^{\text {sat }}, T\right)$ & 8 & 0.03562 & 0.03710 & 0.0452 & 0.01657 \\
$a_{w}^{\text {sat }}(T)$ & 8 & 0.04688 & 0.1043 & 0.1137 & 0.05426 \\
$a_{w}\left(x_{o 1}, x_{o 2}\right)$ & 2 & 0.02011 & 0.06268 & 0.07961 & 0.01548 \\
\hline
\end{tabular}

included in the model comparison, Sect. 4.4. The temperature interval for the solubility and activity data was from $273.15 \mathrm{~K}$ to $353.15 \mathrm{~K}$, but sometimes data were available only at $298.15 \mathrm{~K}$.

The organic-electrolyte data includes water activities as a function organic and electrolyte concentrations at constant temperature. The temperatures given in the different sources were between $293.15 \mathrm{~K}$ and $298.15 \mathrm{~K}$. The last data type was water activity and concentrations in saturated water-organicelectrolyte solution at $297.15 \mathrm{~K}$. Again, instead of actually calculating solubilities, we calculated activities with given concentrations and then compared experimental and calculated water activities, organic activities and activities calculated from the melting enthalpies, and product of ion activities and solubility products. Oxalic acid saturation activities were not included in the fitting, because the melting enthalpy may be inaccurate.

\subsection{Deviations from experimental data}

In this section we examine the accuracies of the fitted models by comparing experimental and calculated water activities, solubilities and mean activity coefficients. Most of the experimental data was already used in the fitting, but also some new data sets are introduced. Deviations from experimental values were calculated for different data types as means of average absolute deviations of the data sets, similarly as in Sect. 3.2.

\subsubsection{Deviations for non-electrolyte solutions}

The data types for non-electrolyte solutions are water activity in organic-water solution as a function of organic mole fraction $\left(a_{w}\left(x_{o}\right)\right)$, organic solubility as a function of temperature $\left(x_{o}^{\text {sat }}(T)\right)$, water saturation activity as a function of solubility and temperature $\left(a_{w}\left(x_{o}^{\mathrm{sat}}, T\right)\right)$, water saturation activity as a function of temperature $\left(a_{w}^{\text {sat }}(T)\right)$ and water activity in binary organic solution as a function of mole fractions $\left(a_{w}\left(x_{o 1}, x_{o 2}\right)\right)$. Mixtures and data sources for these data types are given in the Table 4.

Because all fitted models have the same UNIFAC parameters in non-electrolyte solutions, our model deviations are compared with those of three other UNIFAC-based nonelectrolyte models. The three other models are the UNIFAC part of the original Ming and Russell model, the original UNIFAC, and UNIFAC fitted by Peng et al. (2001). Parameters for the original UNIFAC are from Hansen et al. (1991). Peng et al. (2001) fitted new UNIFAC interaction parameters for $\mathrm{OH}, \mathrm{H}_{2} \mathrm{O}$ and $\mathrm{COOH}$, and the remaining parameters are the same as in the original UNIFAC. The experimental water activity data in Peng et al. (2001) fitting was also used in the fitting of our model parameters (Table 4). Deviations for our refitted UNIFAC model and the three other UNIFAC-based models from the literature are given in Table 5.

The original UNIFAC shows the biggest deviations for all data types, but the original Ming and Russell model performs only slightly better. The present UNIFAC as well as that of Peng et al. (2001) have deviations that are usually less than half of the deviations of the original UNIFAC. Peng et al. (2001) UNIFAC has the smallest deviations for three data types and our model for two data types. Experimental and calculated water activities and organic solubilities for four organic species are presented in Fig. 1.

4.4.2 Deviations in electrolyte and organic-electrolyte so-
lutions

Data types for the nine possible electrolyte-water mixtures are the same as in the comparison of the previously published models (Table 2). The only water-organic-electrolyte data type in this model comparison is water activity in organicelectrolyte-water mixtures as a function of mole fractions and salt molality $\left(a_{w}(x, m)\right)$. The data sources and mixtures are given in the Table 4.

Model deviations and number of data sets are given in Table 6. Because the fitted UNIFAC is not suitable for ion activities, it was not used for the three data types in which ion activities are required. The number of experimental data sets is the same for all models except that LIFAC failed in $a_{w}^{\text {sat }}(T)$ calculation for $\left(\mathrm{NH}_{4}\right)_{2} \mathrm{SO}_{4}$. Originally, there were six data sets for solubility $\left(m^{\text {sat }}(T)\right)$, but LIFAC failed to calculate the solubility of $\left(\mathrm{NH}_{4}\right)_{2} \mathrm{SO}_{4}$ at temperatures below $42^{\circ} \mathrm{C}$ (which also prevented the calculation of the $a_{w}^{\text {sat }}(T)$ of $\left.\left(\mathrm{NH}_{4}\right)_{2} \mathrm{SO}_{4}\right)$. 
Table 6. Experimental single electrolyte and organic-electrolyte data types, number of mixtures (N) and deviations for the fitted models. Sources for experimental single electrolyte data are given in the Table 2 and sources for organic-electrolyte data are given in the Table 4. The unit for deviations in solubility data $\left(m^{\text {sat }}(T)\right)$ is $\mathrm{mol} / \mathrm{kg}$.

\begin{tabular}{llllll}
\hline Data type & $\mathrm{N}$ & UNIFAC & LIFAC & Ming and Russell & Ext. UNIFAC \\
\hline$\gamma_{ \pm}(m)$ & 9 & & 0.1279 & 0.07168 & 0.5023 \\
$a_{w}(m)$ & 9 & 0.02509 & 0.009838 & 0.001104 & 0.01390 \\
$m^{\text {sat }}(T)$ & 5 & & 5.323 & 1.019 & 1.512 \\
$a_{w}\left(m^{\text {sat }}, T\right)$ & 2 & 0.01152 & 0.01582 & 0.01801 & 0.02421 \\
$a_{w}^{\text {sat }}(T)$ & 6 & & 0.01744 & 0.01219 & 0.02521 \\
$a_{w}(x, m)$ & 11 & 0.02824 & 0.01798 & 0.05555 & 0.04546 \\
\hline
\end{tabular}
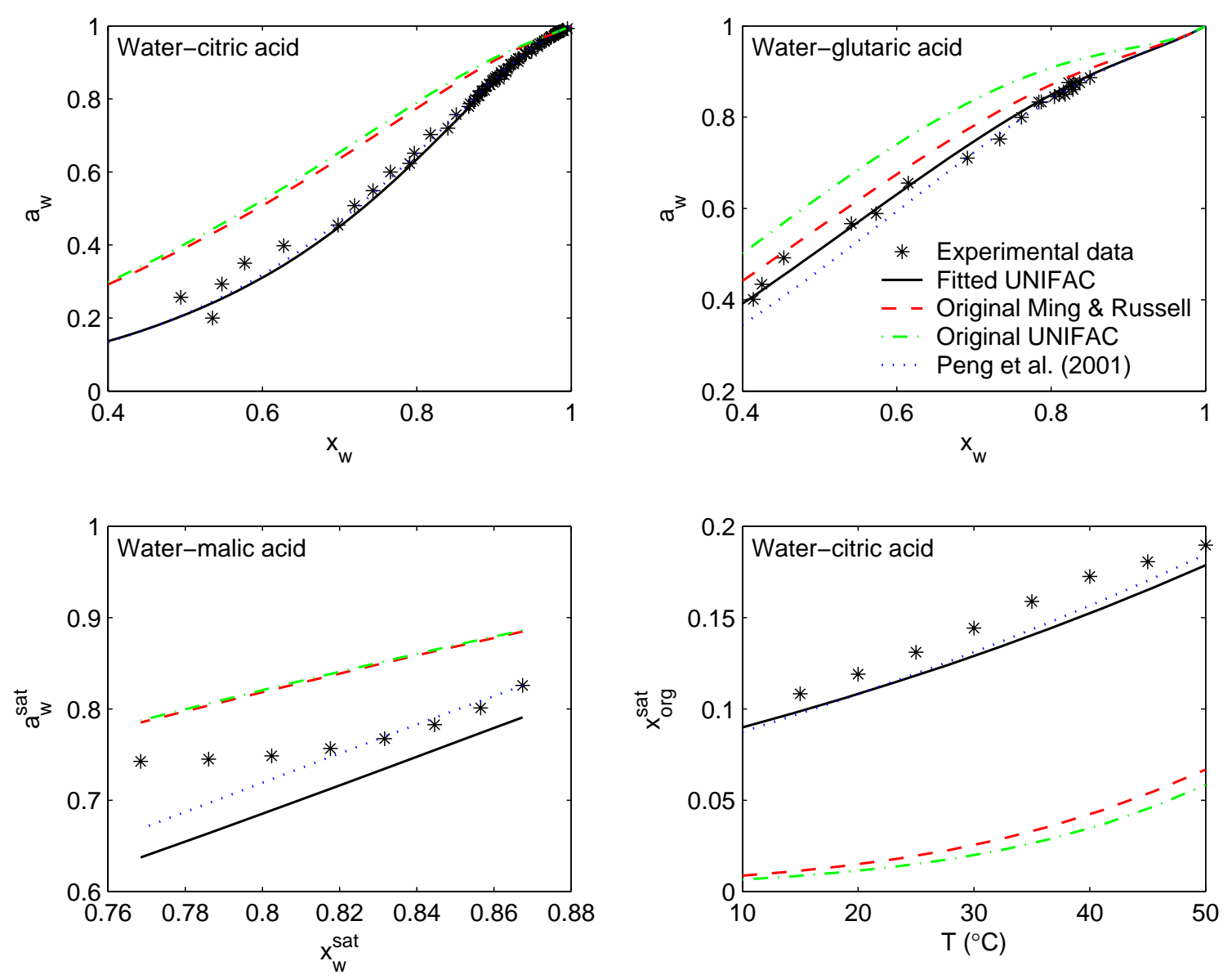

Fig. 1. Experimental and calculated water activities $\left(a_{w}\right)$ in aqueous citric acid and glutaric acid solutions as a function of water mole fraction $\left(x_{w}\right)$ at $298.15 \mathrm{~K}$, experimental and calculated water activities in saturated water-malic acid solution $\left(a_{w}^{\text {sat }}\right)$ as a function of water mole fraction $\left(x_{w}^{\mathrm{sat}}\right)$ at temperatures from $50^{\circ} \mathrm{C}$ to $15^{\circ} \mathrm{C}$ with $5^{\circ} \mathrm{C}$ intervals, and saturation mole fraction of citric acid $\left(x_{\mathrm{org}}^{\mathrm{sat}}\right)$ as a function of temperature $(T)$. Experimental water activity data for citric acid is from Maffia and Meirelles (2001); Peng et al. (2001); Apelblat et al. (1995a,b); Levien (1955) and data for glutaric acid is from Peng et al. (2001). Solubility and water saturation activity data is from Apelblat et al. (1995a).

On the other hand, the other models failed to calculate the solubility of $\mathrm{NH}_{4} \mathrm{NO}_{3}$ at temperatures above $40^{\circ} \mathrm{C}$.

The fitted (and the original) Ming and Russell model reduce to the accurate Clegg et al. (1992) electrolyte model in the single electrolyte solutions, so it is no surprise that the model deviations are the smallest for four of the five single electrolyte data types. Extended UNIFAC has only a simple Debye-Hückel part for electrolytes, so considering 

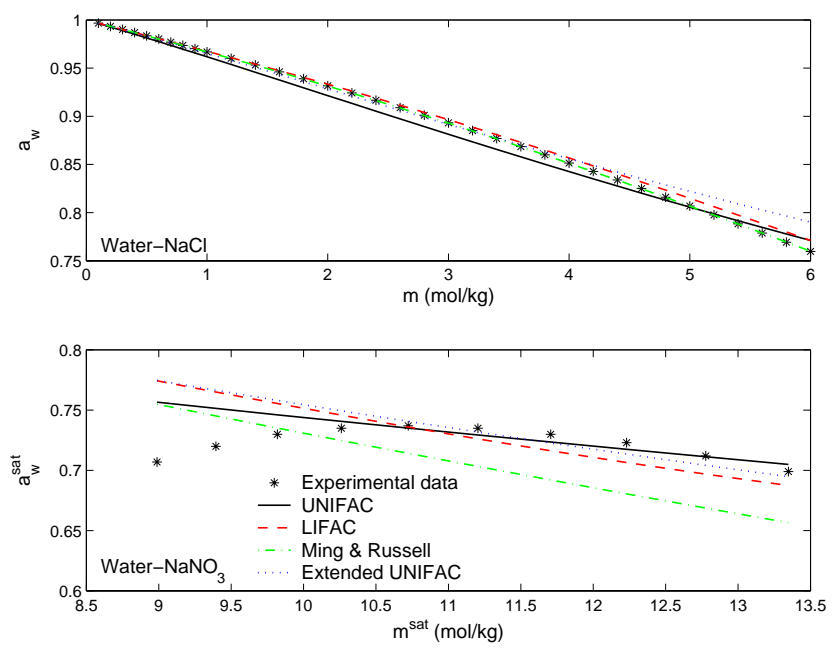

Fig. 2. Experimental and calculated water activities $\left(a_{w}\right)$ in aqueous $\mathrm{NaCl}$ solution as a function of molality $(m)$ at $298.15 \mathrm{~K}$, and water activities in saturated water- $\mathrm{NaNO}_{3}$ solution $\left(a_{w}^{\text {sat }}\right)$ as a function of saturation molality $\left(\mathrm{m}^{\text {sat }}\right)$ at temperatures from $5^{\circ} \mathrm{C}$ to $50^{\circ} \mathrm{C}$ with $5^{\circ} \mathrm{C}$ intervals. Experimental data for $\mathrm{NaCl}$ is from Robinson and Stokes (1959) and for $\mathrm{NaNO}_{3}$ from Apelblat and Korin (1998a).

the simplicity of the model, the deviations for water and ion activities are surprisingly small. UNIFAC shows the smallest deviation for one single electrolyte data type and LIFAC shows the smallest deviation for the one organic-electrolyte data type. For comparison, deviation for the original Ming and Russell model in $a_{w}(x, m)$ data type is 0.07414 , which is bigger than the deviations for the fitted models. Moreover, the original model has parameters only for nine of the eleven mixtures.

Even if both the original and the fitted Ming and Russell models are accurate for electrolyte solutions, their deviations in organic-electrolyte mixtures are quite big compared to the deviations of the other models. The main reason for this is that the original and the fitted Ming and Russell models have few fitting parameters for organic-electrolyte interactions.

The MR part of LIFAC is somewhat problematic for concentrated mixtures. In the MR part, the logarithms of activity coefficients are calculated as sums of terms which are proportional to the fitting parameters, ion molalities and ionic strength. Because these terms have quite large numerical values, a small change in the interaction parameters or molality can cause very big change to activity coefficients. This was the main reason for limiting electrolyte molalities to $30 \mathrm{~mol} / \mathrm{kg}$.

Experimental and calculated water activities, electrolyte solubilities and mean activity coefficients in single electrolyte solutions are presented in Figs. 2 and 3. Experimental and calculated water activities in aqueous organic-electrolyte solutions are presented in Fig. 4, where the original Ming and Russell model is included for comparison.
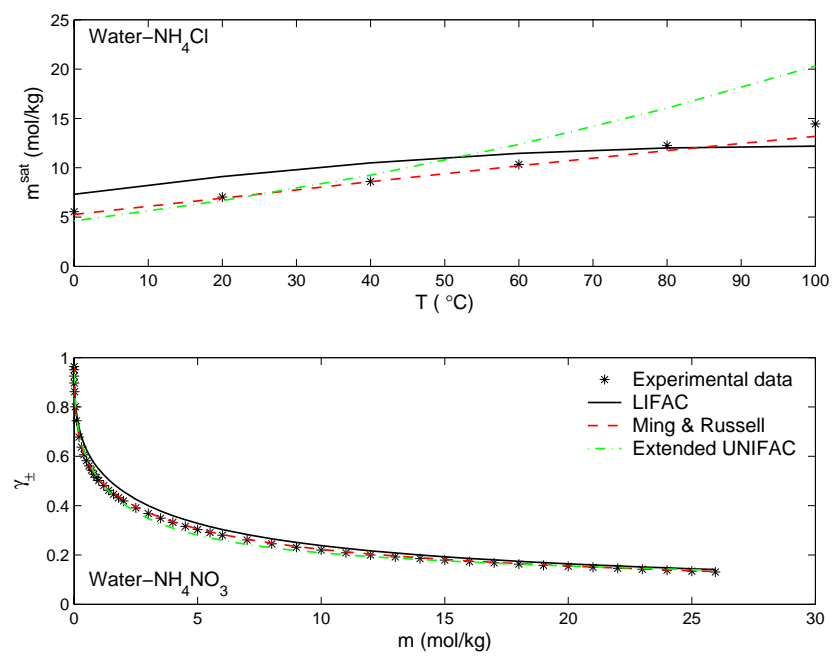

Fig. 3. Experimental and calculated $\mathrm{NH}_{4} \mathrm{Cl}$ solubilities $\left(m^{\text {sat }}\right)$ as a function of temperature $(T)$, and $\mathrm{NH}_{4} \mathrm{NO}_{3}$ mean activity coefficients $\left(\gamma_{ \pm}\right)$as a function of molality $(m)$ at $298.15 \mathrm{~K}$. Experimental solubility data is from ChemDAT - The Merck Chemical Databases (http://chemdat.merck.de/mda/int_en/labtool/index.html) and mean activity coefficient data is from Hamer and Wu (1972).
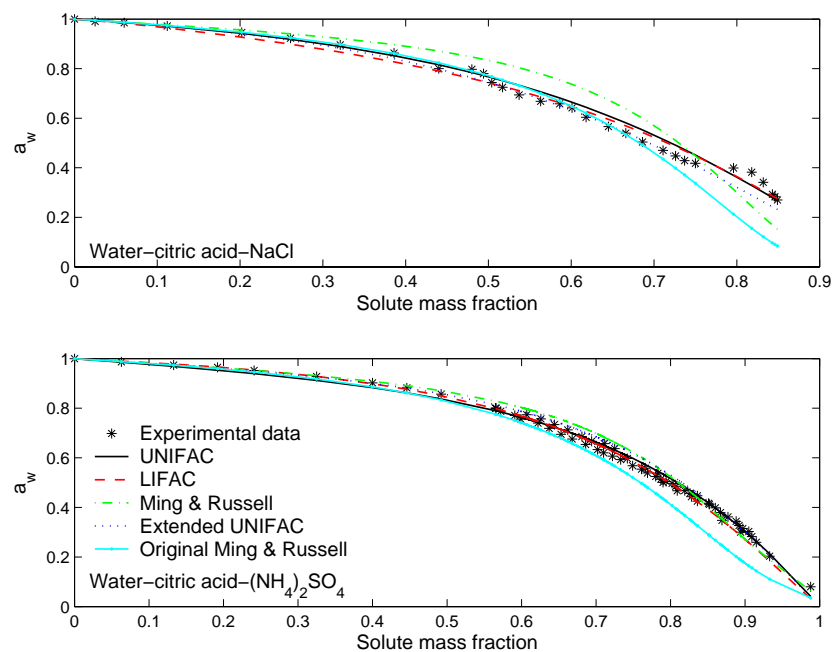

Fig. 4. Experimental and calculated water activities $\left(a_{w}\right)$ in waterorganic-electrolyte mixtures as a function of solute mass fraction when organic and salt mole fractions are equal. Experimental data is from Choi and Chan (2002). This data is measured at temperatures between 293.15 and $296.15 \mathrm{~K}$, and activities were calculated using $295 \mathrm{~K}$. 

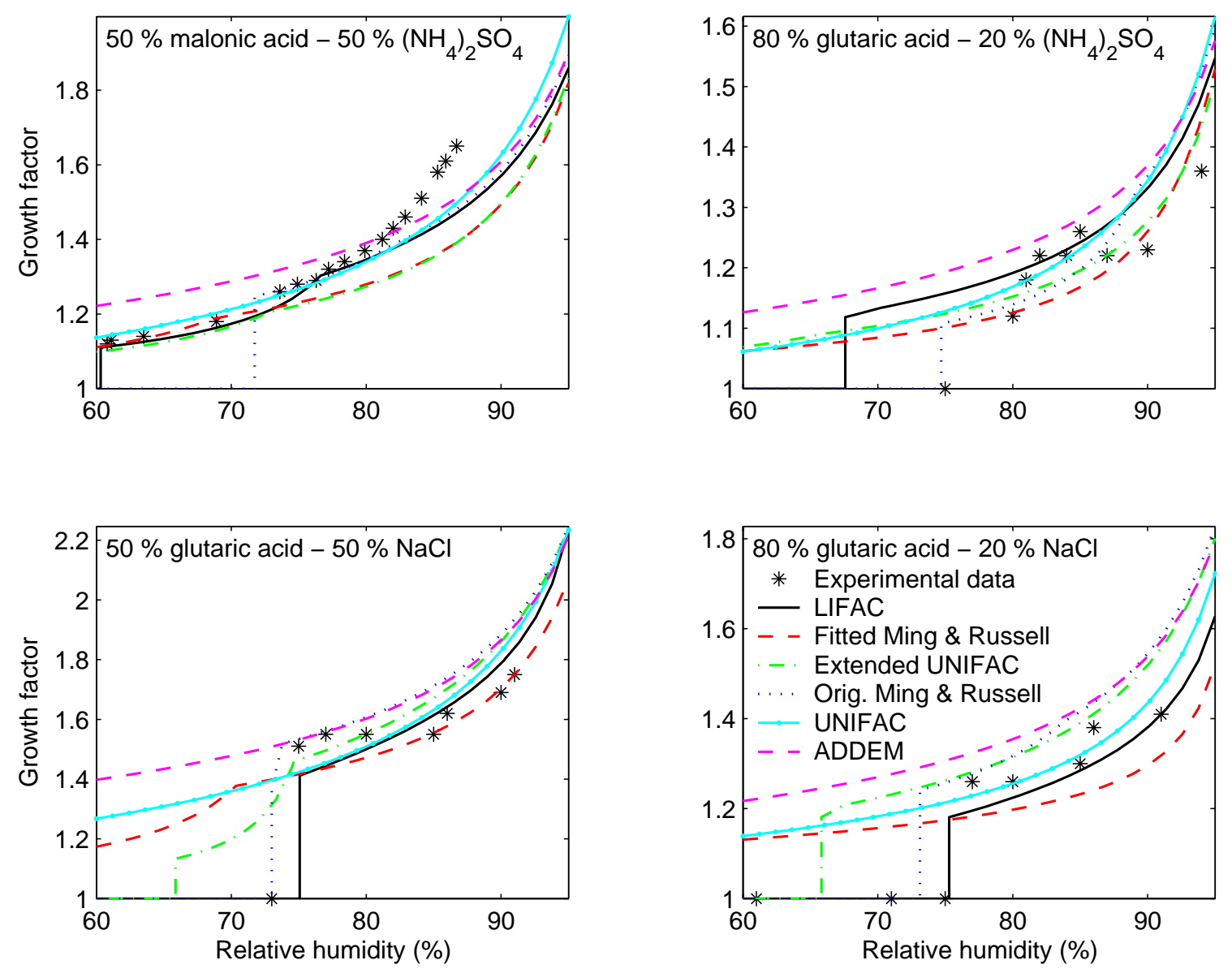

Fig. 5. Experimental and calculated hygroscopic growth factors as a function of relative humidity for four dry $100 \mathrm{~nm}$ organic-salt particles. Experimental data for malonic acid- $\left(\mathrm{NH}_{4}\right)_{2} \mathrm{SO}_{4}$ is from Hämeri et al. (2002) and data for other systems is from Cruz and Pandis (2000). The temperature is $298.15 \mathrm{~K}$ in Hämeri et al. (2002) data and 297.15 K in Cruz and Pandis (2000) data.

\subsection{Growth factors for organic-salt particles}

The accuracies and predictive capabilities of the fitted models are tested by calculating growth factors for organic-salt particles. For comparison, growth factors were also calculated with the original Ming and Russell model and ADDEM (Topping et al., 2005). Our UNIFAC and ADDEM (Aerosol Diameter Dependent Equilibrium Model) are not suitable for solubility calculations, so growth factors were calculated as if particles were dissolved at all relative humidities (supersaturated solutions). In ADDEM, the water content in mixed organic-electrolyte solutions is calculated from the water contents in organic-water and electrolyte-water solutions by using the ZSR (Stokes and Robinson, 1966) approach, in which organic-electrolyte interactions are ignored. The organic-water and electrolyte-water solutions are modelled with UNIFAC parameters from Peng et al. (2001) and Clegg et al. (1992) model respectively. Experimental and calculated growth factors for four different $100 \mathrm{~nm}$ organic-salt particles are plotted in Fig. 5. The dry particle composition is given as weight fractions.
Because there were few experimental data for electrolyte and organic activities, some deviations were expected to occur in the solubility calculations. The most difficult part in calculating of growth factors is the calculation of MDRH, where both the electrolyte and the organic species are saturated. It seems that most of the fitted models predict too low MDRH, but this depends very much on the organicelectrolyte mixture. At MDRH, when the liquid phase is formed, some fraction of the electrolyte or the organic species usually stays in the solid phase. When the relative humidity increases, condensing water dissolves part of the solid phase and this is balanced by further condensation of water resulting in faster growth compared to the pure liquid droplets. This kind of behaviour can be seen in the calculated growth factors. However, this behaviour is not seen in the experimental data, because variations in measurement data can be bigger than the effect of the dissolving solid phase to the growth factors. After the deliquescence, the models predict quite similar growth factors for three mixtures. The one exception is $80 \%$ glutaric acid $-20 \% \mathrm{NaCl}$ mixture, where variations are quite large. However, the average 
of the predictions is quite close to the experimental values. In the case of $50 \%$ glutaric acid $-50 \%\left(\mathrm{NH}_{4}\right)_{2} \mathrm{SO}_{4}$ mixture, all predicted growth factors are smaller than the experimental values at relative humidities above $85 \%$.

Compared to the experimental accuracies of the other data types used in the model comparisons, there are much more uncertainties in the experimental growth factors. Cruz and Pandis (2000) data include few experimental values, and for example, in the case of $80 \%$ glutaric acid $-20 \%\left(\mathrm{NH}_{4}\right)_{2} \mathrm{SO}_{4}$ particles, there seems to be a local maximum in the growth factors between 80 and $90 \%$ relative humidities, but this should not be possible. Data from Hämeri et al. (2002) is fairly smooth, however, Prenni et al. (2003) measured smaller growth factors for the same mixture at $303.15 \mathrm{~K}$ at $R H$ 's above $85 \%$. These values would have been closer to the model predictions.

Other causes for the observed deviations between model predictions and experimental data are errors caused by approximation of solution densities and surface tensions. The density approximation can cause deviations to calculated droplet volume and to the Kelvin effect, where also the surface tension is needed. Because the diameters of the solid particles are $100 \mathrm{~nm}$, the Kelvin term has only a small effect on the growth factors and MDRH. The volume approximation would be accurate for insoluble particles, and in the case of soluble particles, the effect of predicted water activity to liquid water content and through this to liquid volume is much bigger than the effect of solution density.

\section{Summary and conclusions}

In the first part of this paper we selected five different waterorganic-electrolyte activity coefficient models from the literature. Only one of these models includes organics and electrolytes that are relevant in atmospheric modelling. Organics in the other models were organic solvents, such as alcohols. Furthermore, important atmospheric electrolytes (e.g. $\mathrm{H}^{+}$) were missing form some of the models. Model deviations were calculated for different types of experimental single electrolyte data (Table 3) in order to assess model accuracy and suitability for atmospheric modelling.

In the second part of this paper four of the tested models were selected to be extended for organic-electrolyte mixtures relevant in the atmosphere (e.g. ammonia, sulphate, dicarboxylic acids and citric acid). The model selection was based on the model deviations and the predictive capabilities. Some of the selected models were modified if it was found useful, and both new and existing mixture parameters were fitted to experimental data. Model deviations were calculated for different non-electrolyte and electrolyte data types (Tables 5 and 6). For comparison, deviations were calculated also for some other models, which are suitable for these mixtures. Furthermore, model predictions and experimental data are presented in Figs. 1, 2, 3 and 4. Finally, model predic- tions for growth factors of organic-electrolyte particles were compared to experimental data (Fig. 5).

Our results indicate that if experimental data is available, most of the predictive organic-electrolyte models can be successfully extended to atmospheric mixtures by fitting of new parameters. Because the organic fraction in atmospheric mixtures can be composed of many different compounds and there are few experimental data available for fitting, predictive models are especially useful in atmospheric modelling. For these reasons, only predictive models were selected for fitting.

The biggest problem in the fitting is lack of experimental data for organic activities in all solutions and electrolyte activities in organic-electrolyte solutions. The only organic activity data type was organic solubilities. Similarly, the only electrolyte activity data in ternary solutions was electrolyte solubilities. The biggest problem with this kind of data is that we have activities only at one single concentration. Another problem for organics was that melting enthalpies needed in solubility calculations were not found for all organics, but had to be estimated from other thermodynamic constants.

There are several accurate activity coefficient models for electrolytes and some of them are suitable for atmospheric mixtures. However, without fitting of new parameters, few of the non-electrolyte models are actually suitable for atmospheric organics. For example, the original UNIFAC showed much bigger deviations than our and the Peng et al. (2001) UNIFAC versions. There are very few models that are suitable for organic-electrolyte mixtures of atmospheric interest. We used one model (Ming and Russell, 2002) not fitted by us in the model comparison, and this model had bigger deviations for water activities in organic-electrolyte solution than our fitted models. There are some methods in which fitting parameters are not needed, for example ZSR (Stokes and Robinson, 1966) based ADDEM (Topping et al., 2005) and the Clegg et al. (2001) method, but deviations were not calculated for them. However, ADDEM was used in predicting growth factors for organic-electrolyte particles. Compared with the predictions of our models and experimental data, ADDEM overestimates growth factors in the systems studied.

If only water activities are needed, the simplest fitted model, i.e. UNIFAC, is reasonably accurate. For example, in the growth factor calculations, our UNIFAC performs better than most of the other models. In addition to good accuracy, UNIFAC is also very fast in computer simulations. In addition to the UNIFAC part, Extended UNIFAC has a simple electrolyte part, which makes this model suitable for calculating electrolyte activities in dilute single electrolyte solutions. However, because electrolyte activities were included in the fitting, deviations in organic-electrolyte solutions are bigger than those of UNIFAC. In addition to the simple electrolyte model and UNIFAC, LIFAC has a part describing non-electrolyte-ion interactions. This improves model accuracy in both electrolyte and organic-electrolyte solutions, 
where LIFAC has the smallest deviation. Because the fitted (and original) Ming and Russell model has few fitting parameters for the organic-electrolyte interactions, the model is close to an electrolyte model. For this reason, model deviations are the biggest in organic-electrolyte solutions, but small in single electrolyte solutions. Thanks to the accurate Clegg et al. (1992) electrolyte part, this model is suitable for complex mixtures of electrolytes.

There are very few activity coefficient models for ternary water-organic-electrolyte mixtures of atmospheric interest, and when predictions of our fitted models were compared to experimental data and to predictions of other models, our models performed well. Most of the published organicelectrolyte models are fitted for a few different mixtures, but our models had relatively large database in the fitting. In addition to species in the fitting, our predictive models can be used to predict activities for other similar compounds as well. Because there are few experimental data and other models for these mixtures, the fitted models can be very useful.

\section{Appendix A: UNIFAC}

The first model is the same as the original UNIFAC (Fredenslund et al., 1975), except that we introduced new functional groups for ions and organics. This has no effect to the model equations, but new model parameters are needed. Because this new model is not used for ion activities, the reference states are the same as in the original UNIFAC. However, in the other three fitted models in which ion activities are calculated, ions have different reference states than nonelectrolytes.

UNIFAC (Fredenslund et al., 1975) is so called group contribution method, where chemical species are constructed from functional groups. This reduces the number of fitting parameters and makes the model predictive. Activity coefficient for species $i$ is calculated as a sum of combinatorial and residual contributions

$$
\ln \gamma_{i}=\ln \gamma_{i}^{\mathrm{C}}+\ln \gamma_{i}^{\mathrm{R}}
$$

The combinatorial contribution is calculated with the equation

$$
\ln \gamma_{i}^{\mathrm{C}}=1-V_{i}+\ln V_{i}-\frac{z}{2} q_{i}\left(1-\frac{V_{i}}{F_{i}}+\ln \left(\frac{V_{i}}{F_{i}}\right)\right)
$$

where $V_{i}=\frac{r_{i}}{\sum_{k} r_{k} x_{k}}, F_{i}=\frac{q_{i}}{\sum_{k} q_{k} x_{k}}$ and $z=10 . x_{i}$ is mole fraction, $q_{i}=\sum_{k} v_{k}^{(i)} Q_{k}$ is area parameter, $r_{i}=\sum_{k} v_{k}^{(i)} R_{k}$ is volume parameter and $v_{k}^{(i)}$ is the number of functional group $k$ in species $i$. The only parameters in the combinatorial part are the pure component area $\left(Q_{k}\right)$ and volume $\left(R_{k}\right)$ parameters for sub groups.

The residual contribution is calculated with the equation

$$
\ln \gamma_{i}^{\mathrm{R}}=\sum_{k} v_{k}^{(i)}\left[\ln \Gamma_{k}-\ln \Gamma_{k}^{(r e f, i)}\right]
$$

where $\Gamma_{k}$ describes the effect of sub group $k$ on the activity coefficient of component $i$. The latter term in the sum describes the effect of sub group $k$ in the reference state of component $i$, making the activity coefficient unity at the reference state. The reference state for non-electrolytes is liquid of pure component $i$. In our electrolyte models, the reference state for ion $i$ is infinitely dilute aqueous solution. The equation for $\Gamma_{k}$ is

$$
\begin{aligned}
\ln \Gamma_{k}= & Q_{k}\left[1-\ln \left(\sum_{m} \frac{X_{m} Q_{m}}{\sum_{n} X_{n} Q_{n}} \Psi_{m k}\right)-\right. \\
& \left.\sum_{m}\left(\frac{X_{m} Q_{m} \Psi_{k m}}{\sum_{n} X_{n} Q_{n} \Psi_{n m}}\right)\right]
\end{aligned}
$$

where $X_{k}=\frac{\sum_{j} v_{k}^{(j)} x_{j}}{\sum_{j} \sum_{m} v_{m}^{(j)} x_{j}}$ is mole fraction of group $k$ in the mixture, $\Psi_{k m}=\exp \left(-\frac{a_{k m}}{T}\right)$ and $a_{k m}$ is the group interaction parameter for main groups $k$ and $m$. Most of the functional groups (main groups) have sub groups which have the same interaction parameters, but different $Q_{k}$ and $R_{k}$. For example the main group $\mathrm{CH}_{\mathrm{n}}$ has sub groups $\mathrm{CH}_{3}, \mathrm{CH}_{2}, \mathrm{CH}$ and $\mathrm{C}$.

The group volume and surface area parameters can be calculated from the molecular sizes of the functional groups. This is difficult for ions because for example the $\mathrm{H}^{+}$ion is very small compared to the sizes of organic groups. These parameters could also be fitted, but this can lead to very small or high values. In the new UNIFAC model, the group volume and surface area parameters for non-electrolytes are the same as in the original UNIFAC, and parameters for ions were taken from the literature. Group volume and surface area parameters for all functional groups are given in Table 7. Fitted interaction parameters for non-electrolytes are in Table 8 . These interaction, surface area and volume parameters are the same for all fitted models where parameters are needed. Ion-organic interaction parameters were also fitted for this model and are given in Table 9. Ion-ion interaction parameters were set to zero.

\section{Appendix B: LIFAC}

The second model is the same as the original LIFAC (Yan et al., 1999), with the addition of new functional groups for electrolytes and organics. The main and the sub groups are same as in our UNIFAC model. Activity coefficients in LIFAC (Yan et al., 1999) are calculated as a sum of three contributions: long range (LR), middle range (MR) and short range (SR).

$\ln \gamma_{i}=\ln \gamma_{i}^{\mathrm{LR}}+\ln \gamma_{i}^{\mathrm{MR}}+\ln \gamma_{i}^{\mathrm{SR}}$

The LR contribution is calculated with a Debye-Hückel term, the MR contribution is calculated with virial equation and the SR contribution is calculated with UNIFAC. When electrolyte concentration is zero, the LR and MR contributions for all species are zeros and the model reduces to UNIFAC. 
Table 7. UNIFAC group volume $R_{k}$ and surface area $Q_{k}$ parameters for the modelled electrolytes and non-electrolytes. Parameters for the non-electrolytes are the same as in the original UNIFAC from Hansen et al. (1991). Parameters for $\mathrm{Na}^{+}, \mathrm{NH}_{4}^{+}, \mathrm{Cl}^{-}$and $\mathrm{NO}_{3}^{-}$are from Yan et al. (1999). Parameters for $\mathrm{H}^{+}$are the same as for most cations in Yan et al. (1999) and parameters for $\mathrm{SO}_{4}^{2-}$ are the same as for $\mathrm{NO}_{3}^{-}$.

\begin{tabular}{llll}
\hline Main group & Sub group & $R_{k}$ & $Q_{k}$ \\
\hline $\mathrm{H}_{2} \mathrm{O}$ & $\mathrm{H}_{2} \mathrm{O}$ & 0.9200 & 1.400 \\
$\mathrm{CH}_{\mathrm{n}}$ & $\mathrm{CH}_{2}$ & 0.6744 & 0.540 \\
$\mathrm{CH}_{\mathrm{n}}$ & $\mathrm{CH}$ & 0.4469 & 0.228 \\
$\mathrm{CH}_{\mathrm{n}}$ & $\mathrm{C}$ & 0.2195 & 0.000 \\
$\mathrm{OH}$ & $\mathrm{OH}$ & 1.0000 & 1.200 \\
$\mathrm{COOH}$ & $\mathrm{COOH}$ & 1.3010 & 1.224 \\
$\mathrm{Na}^{+}$ & $\mathrm{Na}^{+}$ & 3.0000 & 3.000 \\
$\mathrm{NH}_{4}^{+}$ & $\mathrm{NH}_{4}^{+}$ & 3.0000 & 3.000 \\
$\mathrm{H}^{+}$ & $\mathrm{H}^{+}$ & 1.0000 & 1.000 \\
$\mathrm{Cl}^{-}$ & $\mathrm{Cl}^{-}$ & 0.9861 & 0.992 \\
$\mathrm{NO}_{3}^{-}$ & $\mathrm{NO}_{3}^{-}$ & 1.6400 & 1.600 \\
$\mathrm{SO}_{4}^{2-}$ & $\mathrm{SO}_{4}^{2-}$ & 1.6400 & 1.600 \\
\hline
\end{tabular}

The long range contribution is calculated with DebyeHückel theory. This part has no fitting parameters, but only pure solvent properties. The solvent is a mixture of water and organic compound, and its properties are calculated from pure component properties weighted with salt free volume fraction $\phi_{s}^{\prime}=\frac{x_{s}^{\prime} \frac{M_{s}}{\rho_{s}}}{\sum_{i \neq s a l t} x_{i}^{\prime} \frac{M_{i}}{\rho_{i}}}$, where $M_{s}(\mathrm{~kg} / \mathrm{mol})$ is molecular weight, $\rho_{s}\left(\mathrm{~kg} / \mathrm{m}^{3}\right)$ is density and $x_{s}^{\prime}$ is salt free mole fraction of pure solvent $s$. Solvent $(s)$ and ion $(i)$ activity coefficients are calculated with the equations

$$
\begin{aligned}
\ln \gamma_{s}^{\mathrm{LR}}= & \frac{2 A M_{s} \rho}{b^{3} \rho_{s}}\left(1+b \sqrt{I}-\frac{1}{1+b \sqrt{I}}-\right. \\
& 2 \ln (1+b \sqrt{I})) \\
\ln \gamma_{i}^{\mathrm{LR}}= & \frac{-z_{i}^{2} A \sqrt{I}}{1+b \sqrt{I}}
\end{aligned}
$$

where $\rho=\sum_{s} \phi_{s}^{\prime} \rho_{s}$ is density of the solvent mixture, $z_{i}$ is charge magnitude of ion $i$ and $I=0.5 \sum_{i} m_{i} z_{i}^{2}(\mathrm{~mol} / \mathrm{kg})$ is ionic strength in the molality $(m)$ scale. The Debye-Hückel parameters $A(\sqrt{\mathrm{kg} / \mathrm{mol}})$ and $b(\sqrt{\mathrm{kg} / \mathrm{mol}})$ are calculated with equations

$$
\begin{aligned}
A & =e_{0}^{3} \frac{\left(2 \pi N_{A} \rho\right)^{1 / 2}}{(D k T)^{3 / 2}} \\
b & =a \sqrt{\frac{8 \pi e_{0}^{2} N_{A} \rho}{D k T}}
\end{aligned}
$$

where $e_{0}(\mathrm{C})$ is elementary charge, $N_{A}(1 / \mathrm{mol})$ is Avogadro's constant, $k(\mathrm{~J} / \mathrm{K})$ is Boltzmann constant, $T(\mathrm{~K})$ is tem-
Table 8. Fitted UNIFAC interaction parameters $a_{i j}(\mathrm{~K})$ for the modelled non-electrolytes.

\begin{tabular}{llll}
\hline $\mathrm{i}$ & $\mathrm{j}$ & $a_{i j}$ & $a_{j i}$ \\
\hline $\mathrm{H}_{2} \mathrm{O}$ & $\mathrm{CH}_{\mathrm{n}}$ & 170.22 & 2650.8 \\
$\mathrm{H}_{2} \mathrm{O}$ & $\mathrm{OH}$ & -1.3932 & -407.50 \\
$\mathrm{H}_{2} \mathrm{O}$ & $\mathrm{COOH}$ & -437.73 & 271.04 \\
$\mathrm{CH}_{\mathrm{n}}$ & $\mathrm{OH}$ & 143.48 & 19.236 \\
$\mathrm{CH}_{\mathrm{n}}$ & $\mathrm{COOH}$ & -150.91 & 2693.3 \\
$\mathrm{OH}$ & $\mathrm{COOH}$ & -492.09 & 238.13 \\
\hline
\end{tabular}

perature and $a(\mathrm{~m})$ is the closest approach parameter, here $a=10^{-10} \mathrm{~m}$. Dielectric constant is calculated with equation $D=4 \pi \epsilon_{0} \epsilon_{r}$, where $\epsilon_{0}\left(\mathrm{C}^{2} /(\mathrm{J} \mathrm{m})\right)$ is permittivity of vacuum and $\epsilon_{r}$ is relative permittivity. In the original model, $D$ is dielectric constant of solvent mixture, but because dielectric constants were not available for all organics, we use that of pure water instead.

The middle range contribution is calculated using functional groups, which are the same as in the UNIFAC part. The equations for solvent group $k$ and ion $j$ are

$$
\begin{aligned}
\ln \gamma_{k}^{\mathrm{MR}}= & \sum_{i} B_{k i} m_{i}- \\
& \frac{M_{k} \sum_{k} \sum_{i} v_{k}^{(i)} x_{i}^{\prime}}{M} \sum_{k} \sum_{i}\left[B_{k i}+I B_{k i}^{\prime}\right] x_{k}^{\prime} m_{i}- \\
& M_{k} \sum_{c} \sum_{a}\left[B_{c a}+I B_{c a}^{\prime}\right] m_{c} m_{a} \\
\ln \gamma_{j}^{\mathrm{MR}}= & \frac{1}{M} \sum_{k} B_{j k} x_{k}^{\prime}+\frac{z_{j}^{2}}{2 M} \sum_{k} \sum_{i} B_{k i} x_{k}^{\prime} m_{i}+ \\
& \sum_{i} B_{j i} m_{i}+\frac{z_{j}^{2}}{2} \sum_{c} \sum_{a} B_{c a}^{\prime} m_{c} m_{a}
\end{aligned}
$$

where $B_{j k}(\mathrm{~kg} / \mathrm{mol})$ is interaction coefficient for groups $j$ and $k, B_{j k}^{\prime}\left(\mathrm{kg}^{2} / \mathrm{mol}^{2}\right)$ is derivative of $B_{j k}$ with respect to ionic strength, $M=\sum_{s} x_{s}^{\prime} M_{s}$ is molecular weight of solvent mixture and $M_{k}$ is molecular weight of solvent group $k$, which were calculated from atomic weights. Subscripts $k$, $i, c$ and $a$ denote solvent group, any ion, cation and anion respectively. Symmetric $\left(B_{j k}=B_{k j}\right)$ interaction coefficients are functions of ionic strength

$$
\begin{aligned}
& B_{c a}(I)=b_{c a}+c_{c a} \exp (-\sqrt{I}+0.13 I) \\
& B_{k i}(I)=b_{k i}+c_{k i} \exp (-1.2 \sqrt{I}+0.13 I)
\end{aligned}
$$

where $b_{j k}$ and $c_{j k}$ are interaction parameters for main groups $j$ and $k$. Ion activity coefficients must be normalized to infinite dilution reference state by subtracting the first term in Eq. (B7) calculated with correct reference state 
Table 9. Fitted UNIFAC non-electrolyte-ion interaction parameters $a_{i j}(\mathrm{~K})$. Some parameters are zeros because of lack of experimental data. Water-organic interaction parameters are in the Table 8 , and all ion-ion interaction parameters were set to zero.

\begin{tabular}{llllllllllll}
\hline $\mathrm{i}$ & $\mathrm{j}$ & $a_{i j}$ & $a_{j i}$ & $\mathrm{i}$ & $\mathrm{j}$ & $a_{i j}$ & $a_{j i}$ & $\mathrm{i}$ & $\mathrm{j}$ & $a_{i j}$ & $a_{j i}$ \\
\hline $\mathrm{H}_{2} \mathrm{O}$ & $\mathrm{H}^{+}$ & -1998 & -735.4 & $\mathrm{CH}_{\mathrm{n}}$ & $\mathrm{NH}_{4}^{+}$ & -2.452 & 4478 & $\mathrm{OH}$ & $\mathrm{SO}_{4}^{2-}$ & -1877 & 4062 \\
$\mathrm{H}_{2} \mathrm{O}$ & $\mathrm{Na}^{+}$ & 48.27 & -287.7 & $\mathrm{CH}_{\mathrm{n}}$ & $\mathrm{Cl}^{-}$ & -640.5 & 39.66 & $\mathrm{OH}$ & $\mathrm{NO}_{3}^{-}$ & 39.43 & 189.8 \\
$\mathrm{H}_{2} \mathrm{O}$ & $\mathrm{NH}_{4}^{+}$ & -558.6 & 2817 & $\mathrm{CH}_{\mathrm{n}}$ & $\mathrm{SO}_{4}^{2-}$ & 640.5 & -21.18 & $\mathrm{COOH}$ & $\mathrm{H}^{+}$ & 0 & 0 \\
$\mathrm{H}_{2} \mathrm{O}$ & $\mathrm{Cl}^{-}$ & 48.31 & 132.0 & $\mathrm{CH}_{\mathrm{n}}$ & $\mathrm{NO}_{3}^{-}$ & 17.73 & 3382 & $\mathrm{COOH}$ & $\mathrm{Na}^{+}$ & 1440 & 636 \\
$\mathrm{H}_{2} \mathrm{O}$ & $\mathrm{SO}_{4}^{2-}$ & -1818 & 1620 & $\mathrm{OH}$ & $\mathrm{H}^{+}$ & 0 & 0 & $\mathrm{OOOH}$ & $\mathrm{NH}_{4}^{+}$ & -632.9 & -167.6 \\
$\mathrm{H}_{2} \mathrm{O}$ & $\mathrm{NO}_{3}^{-}$ & 367.6 & 1368 & $\mathrm{OH}$ & $\mathrm{Na}^{+}$ & 1.804 & -12.22 & $\mathrm{COOH}$ & $\mathrm{Cl}^{-}$ & 2135 & -234.9 \\
$\mathrm{CH}_{\mathrm{n}}$ & $\mathrm{H}^{+}$ & 0 & 0 & $\mathrm{OH}$ & $\mathrm{NH}_{4}^{+}$ & -20.09 & 79.73 & $\mathrm{COOH}$ & $\mathrm{SO}_{4}^{2-}$ & -1970 & -526.6 \\
$\mathrm{CH}_{\mathrm{n}}$ & $\mathrm{Na}^{+}$ & -473.0 & 11.07 & $\mathrm{OH}$ & $\mathrm{Cl}^{-}$ & 0.2297 & -423.1 & $\mathrm{COOH}$ & $\mathrm{NO}_{3}^{-}$ & 563.8 & 2533 \\
\hline
\end{tabular}

Table 10. Fitted MR non-electrolyte-ion and cation-anion interaction parameters $b_{i k}(\mathrm{~kg} / \mathrm{mol})$ and $c_{i k}(\mathrm{~kg} / \mathrm{mol})$ for LIFAC. Some parameters are zeros because of lack of experimental data.

\begin{tabular}{llllllllllll}
\hline $\mathrm{i}$ & $\mathrm{k}$ & $b_{i k}$ & $c_{i k}$ & $\mathrm{i}$ & $\mathrm{k}$ & $b_{i k}$ & $c_{i k}$ & $\mathrm{i}$ & $\mathrm{k}$ & $b_{i k}$ & $c_{i k}$ \\
\hline $\mathrm{H}_{2} \mathrm{O}$ & $\mathrm{Na}^{+}$ & -0.02272 & $7.5 \mathrm{e}-6$ & $\mathrm{CH}_{\mathrm{n}}$ & $\mathrm{SO}_{4}^{2-}$ & 0.04104 & -0.09337 & $\mathrm{COOH}$ & $\mathrm{NO}_{3}^{-}$ & 0.1014 & 0.00019 \\
$\mathrm{H}_{2} \mathrm{O}$ & $\mathrm{NH}_{4}^{+}$ & -0.02522 & 0.00107 & $\mathrm{OH}$ & $\mathrm{Na}^{+}$ & -0.00059 & -0.00038 & $\mathrm{COOH}$ & $\mathrm{SO}_{4}^{2-}$ & 0.01679 & -0.1489 \\
$\mathrm{H}_{2} \mathrm{O}$ & $\mathrm{H}^{+}$ & -1.098 & 0.00154 & $\mathrm{OH}$ & $\mathrm{NH}_{4}^{+}$ & -0.2618 & -1.486 & $\mathrm{Na}^{+}$ & $\mathrm{Cl}^{-}$ & 0.2138 & -0.4265 \\
$\mathrm{H}_{2} \mathrm{O}$ & $\mathrm{Cl}^{-}$ & 0.00073 & -0.00683 & $\mathrm{OH}$ & $\mathrm{H}^{+}$ & 0 & 0 & $\mathrm{Na}^{+}$ & $\mathrm{NO}_{3}^{-}$ & 0.07377 & -0.3340 \\
$\mathrm{H}_{2} \mathrm{O}$ & $\mathrm{NO}_{3}^{-}$ & -0.00276 & -0.00272 & $\mathrm{OH}$ & $\mathrm{Cl}^{-}$ & $5.6 \mathrm{e}-6$ & 0.2264 & $\mathrm{Na}^{+}$ & $\mathrm{SO}_{4}^{2-}$ & -0.2365 & 1.938 \\
$\mathrm{H}_{2} \mathrm{O}$ & $\mathrm{SO}_{4}^{2-}$ & -0.04705 & 0.02376 & $\mathrm{OH}$ & $\mathrm{NO}_{3}^{-}$ & -0.01297 & -0.00134 & $\mathrm{NH}_{4}^{+}$ & $\mathrm{Cl}^{-}$ & 0.0506 & -0.0381 \\
$\mathrm{CH}_{\mathrm{n}}$ & $\mathrm{Na}^{+}$ & -0.1891 & $4.2 \mathrm{e}-7$ & $\mathrm{OH}$ & $\mathrm{SO}_{4}^{2-}$ & 0.00302 & 0.01801 & $\mathrm{NH}_{4}^{+}$ & $\mathrm{NO}_{3}^{-}$ & 0.00028 & $6.7 \mathrm{e}-5$ \\
$\mathrm{CH}_{\mathrm{n}}$ & $\mathrm{NH}_{4}^{+}$ & 0.01523 & -0.01184 & $\mathrm{COOH}$ & $\mathrm{Na}^{+}$ & 0.4478 & 0.00064 & $\mathrm{NH}_{4}^{+}$ & $\mathrm{SO}_{4}^{2-}$ & 0.2566 & -1.277 \\
$\mathrm{CH}_{\mathrm{n}}$ & $\mathrm{H}^{+}$ & 0 & 0 & $\mathrm{COOH}$ & $\mathrm{NH}_{4}^{+}$ & -0.1706 & -0.09065 & $\mathrm{H}^{+}$ & $\mathrm{Cl}^{-}$ & 0.3294 & 0.00030 \\
$\mathrm{CH}_{\mathrm{n}}$ & $\mathrm{Cl}^{-}$ & -0.3260 & 2.781 & $\mathrm{COOH}$ & $\mathrm{H}^{+}$ & 0 & 0 & $\mathrm{H}^{+}$ & $\mathrm{NO}_{3}^{-}$ & 0.2091 & -0.3806 \\
$\mathrm{CH}_{\mathrm{n}}$ & $\mathrm{NO}_{3}^{-}$ & -0.04466 & 0.00036 & $\mathrm{COOH}$ & $\mathrm{Cl}^{-}$ & 0.03495 & -0.00022 & $\mathrm{H}^{+}$ & $\mathrm{SO}_{4}^{2-}$ & 0.1401 & -0.00343 \\
\hline
\end{tabular}

concentrations. The MR activity coefficient of solvent $s$ is calculated as a sum of group activity coefficients

$$
\ln \gamma_{s}^{\mathrm{MR}}=\sum_{k} v_{k}^{(s)} \ln \gamma_{k}^{M R}
$$

Some of the MR interaction parameters could have been taken directly from the original model, but because two of the six ions were new, all parameters were fitted. The fitted MR ion-solvent group and cation-anion parameters are given in Table 10.

The short range contribution is calculated with UNIFAC (see Appendix A), but now the infinite dilution reference state is selected for the ions. Because UNIFAC equations give activity coefficients in mole fraction scale, ion activity coefficients are converted to molality scale with equation

$\ln \gamma_{i}^{(m)}=\ln \gamma_{i}^{(x)}-\ln \left(M_{r} / M+M_{r} \sum_{i} m_{i}\right)$

where $M_{r}$ is molecular weight of the reference state solvent and $M$ is molecular weight of the solvent mixture. The SR part UNIFAC parameters are given in the Tables 7 and 8. All non-electrolyte-ion and ion-ion UNIFAC interaction parameters are set to zeros.

\section{Appendix C: Ming and Russell model}

The third model is nearly the same as the original Ming and Russell (2002) model, but one normalization term was dropped and new groups for ions and organics were added. Activity coefficients are calculated as a sum of ion-water interactions (IW) and organic-water/organic-ion interactions (OW/OI).

$\ln \gamma_{i}=\ln \gamma_{i}^{\mathrm{IW}}+\ln \gamma_{i}^{\mathrm{OW} / \mathrm{OI}}$

Ion-water interactions are calculated with the Clegg et al. (1992) model and organic-water/organic-ion interactions are calculated with UNIFAC. If the organic concentration is zero, the new model is reduced to Clegg et al. (1992) model and if the ion concentration is zero the model is reduced to UNIFAC. 
Ion-water interaction are calculated with equations from Clegg et al. (1992) as a sum of LR and SR contributions

$\ln \gamma_{i}^{\mathrm{IW}}=\ln \gamma_{i}^{\mathrm{LR}}+\ln \gamma_{i}^{\mathrm{SR}}$

Ming and Russell calculated the LR and SR activity coefficients using inorganic-only mole fractions $x_{i}^{*}$ (LR* and $\mathrm{SR}^{*}$ ), where organics (subscript $o$ ) are ignored. The activity coefficients were then normalized to the solution mole fractions with the equation

$$
\ln \gamma_{i}^{\mathrm{IW}}=\ln \gamma_{i}^{\mathrm{LR} *}+\ln \gamma_{i}^{\mathrm{SR} *}-2 \ln \left(1-\sum_{o} x_{o}\right)
$$

Even if we use these inorganic-only mole fractions in our modified version, the correction term is ignored. The reason for this is that for non-electrolyte solutions $\left(x_{w}^{*}=1\right.$ and $x_{i o n}^{*}=0$ ) the original model does not reduce to UNIFAC, because the correction term is not zero although it is based on the difference in mole fractions calculated with and without organics. In fact, Ming and Russell (2002) had an error in their computer code which fortuitously ensured that the model reduced to the UNIFAC in non-electrolyte solutions (Y. Ming, personal communication, 2003).

All mole fractions in the IW part are inorganic-only mole fractions, so for clarity, the superscript * is dropped from mole fractions in following model equations. The Clegg et al. (1992) model equations are given in condensed form and all terms that include ternary parameters were ignored. Thus, these equations are valid only if ternary parameters are zeros as is the case e.g. in aqueous sulphuric acid system and in all binary systems. The complete model equations are given in Clegg et al. (1992).

The long range contribution is a sum of Debye-Hückel (DH) contribution and a higher order electrostatic (HOE) contribution to the Debye-Hückel expression.

$$
\ln \gamma_{i}^{\mathrm{LR}}=\ln \gamma_{i}^{\mathrm{DH}}+\ln \gamma_{i}^{\mathrm{HOE}}
$$

The DH contribution for water $w$ and ion $i$ are calculated with equations

$$
\begin{aligned}
\ln \gamma_{w}^{\mathrm{DH}}= & \frac{2 A_{x} I_{x}^{3 / 2}}{1+\rho \sqrt{I_{x}}}- \\
& \sum_{c} \sum_{a} x_{c} x_{a}\left[B_{c a} \exp \left(-\alpha_{c a} \sqrt{I_{x}}\right)+\right. \\
& \left.B_{c a}^{1} \exp \left(-\alpha_{c a}^{1} \sqrt{I_{x}}\right)\right] \\
\ln \gamma_{i}^{\mathrm{DH}}= & \frac{2 A_{x} I_{x}^{3 / 2}}{1+\rho \sqrt{I_{x}}}- \\
& \sum_{c} \sum_{a} x_{c} x_{a}\left[B_{c a} \exp \left(-\alpha_{c a} \sqrt{I_{x}}\right)+\right. \\
& \left.B_{c a}^{1} \exp \left(-\alpha_{c a}^{1} \sqrt{I_{x}}\right)\right]-
\end{aligned}
$$

$$
\begin{aligned}
& z_{i}^{2} A_{x}\left(\frac{2}{\rho} \ln \left(1+\rho \sqrt{I_{x}}\right)+\frac{\sqrt{I_{x}}}{1+\rho \sqrt{I_{x}}}\right)+ \\
& \sum_{j \neq i} x_{j}\left(B_{i j} g\left(\alpha_{i j} \sqrt{I_{x}}\right)+B_{i j}^{1} g\left(\alpha_{i j}^{1} \sqrt{I_{x}}\right)\right)- \\
& \frac{z_{i}^{2}}{2 I_{x}} \sum_{c} \sum_{a} x_{c} x_{a}\left[B _ { c a } \left[g\left(\alpha_{c a} \sqrt{I_{x}}\right)-\right.\right. \\
& \left.\exp \left(-\alpha_{c a} \sqrt{I_{x}}\right)\right]+ \\
& \left.B_{c a}^{1}\left[g\left(\alpha_{c a}^{1} \sqrt{I_{x}}\right)-\exp \left(-\alpha_{c a}^{1} \sqrt{I_{x}}\right)\right]\right]
\end{aligned}
$$

where constant $\rho=13.0$ and the temperature dependent mole fraction scale Debye-Hückel parameter $A_{x}$ has a value 2.917 at $298.15 \mathrm{~K} . I_{x}$ is ionic strength in mole fraction scale and function $g(x)=\frac{2(1-(1+x) \exp (-x))}{x^{2}}$. Most of the symmetric $\left(B_{i j}=B_{j i}\right)$ parameters are zeros: $B_{c c}=B_{a a}=B_{c c}^{1}=B_{a a}^{1}=0$ and $\alpha_{c c}=\alpha_{a a}=\alpha_{c c}^{1}=\alpha_{a a}^{1}=0$. The remaining model parameters for DH part are $B_{c a}, B_{c a}^{1}, \alpha_{c a}$ and $\alpha_{c a}^{1}$.

The HOE contribution for water $w$ and ion $i$ is needed if we have more than two ions (here only in the case of aqueous sulphuric acid). The equations are

$$
\begin{aligned}
& \ln \gamma_{w}^{\mathrm{HOE}=}-2 \sum_{c} \sum_{<c^{\prime}} x_{c} x_{c^{\prime}}\left(\vartheta_{c c^{\prime}}+I_{x} \vartheta_{c c^{\prime}}^{\prime}\right)- \\
& 2 \sum_{a} \sum_{<a^{\prime}} x_{a} x_{a^{\prime}}\left(\vartheta_{a a^{\prime}}+I_{x} \vartheta_{a a^{\prime}}^{\prime}\right) \\
& \ln \gamma_{i}^{\mathrm{HOE}=} 2 \sum_{j \neq i} x_{j}\left[\vartheta_{i j}-x_{i}\left(\vartheta_{i j}+\vartheta_{i j}^{\prime}\left(I_{x}-\frac{z_{i}^{2}}{2}\right)\right)\right]- \\
& 2 \sum_{c \neq i} \sum_{<c^{\prime} \neq i} x_{c} x_{c^{\prime}}\left(\vartheta_{c c^{\prime}}+\vartheta_{c c^{\prime}}^{\prime}\left(I_{x}-\frac{z_{i}^{2}}{2}\right)\right)- \\
& 2 \sum_{a \neq i} \sum_{<a^{\prime} \neq i} x_{a} x_{a^{\prime}}\left(\vartheta_{a a^{\prime}}+\right. \\
&\left.\vartheta_{a a^{\prime}}^{\prime}\left(I_{x}-\frac{z_{i}^{2}}{2}\right)\right)
\end{aligned}
$$

where subscript $j$ includes all cations if $i$ is a cation or all anions if $i$ is a anion, and

$$
\begin{aligned}
\vartheta_{i j} & =\frac{z_{i} z_{j}}{4 I_{x}}\left[J\left(x_{i j}\right)-\frac{1}{2} J\left(x_{i i}\right)-\frac{1}{2} J\left(x_{j j}\right)\right] \\
J\left(x_{i j}\right) & =\frac{x_{i j}}{4+C_{1} x_{i j}^{C_{2}} \exp \left(C_{3} x_{i j}^{C_{4}}\right)} \\
x_{i j} & =6 z_{i} z_{j} A_{x} \sqrt{I_{x}}
\end{aligned}
$$

The constants are $C_{1}=4.581, C_{2}=-0.7237, C_{3}=-0.012$ and $C_{4}=0.528$. Derivatives are $\vartheta_{i j}^{\prime}=\frac{\partial \vartheta_{i j}}{\partial I_{x}}$ and $J^{\prime}\left(x_{i j}\right)=\frac{\partial J\left(x_{i j}\right)}{\partial x_{i j}}$. The HOE part has no fitting parameters. 
Table 11. Clegg et al. (1992) model parameters $B_{c a}, a_{c a}, W_{c a}, U_{c a}, V_{c a}, B_{c a}^{1}, a_{c a}^{1}$ for the IW part of the Ming and Russell model. Parameters for $\mathrm{H}_{2} \mathrm{SO}_{4}$ and $\mathrm{HCl}$ are from Clegg and Brimblecombe (1995) and Clegg et al. (1992) respectively, and the remaining parameters are from Clegg et al. (1998b).

\begin{tabular}{llllllll}
\hline & $B_{c a}$ & $a_{c a}$ & $W_{c a}$ & $U_{c a}$ & $V_{c a}$ & $B_{c a}^{1}$ & $a_{c a}^{1}$ \\
\hline $\mathrm{H}^{+}-\mathrm{SO}_{4}^{2-}$ & -46.7149774 & 9.5 & -9.88620169 & -5.45640111 & -5.98318162 & 0 & 0 \\
$\mathrm{H}^{+}-\mathrm{HSO}_{4}^{-}$ & 38.2460542 & 17.0 & -11.1152714 & -1.03606797 & -3.58228743 & 0 & 0 \\
$\mathrm{H}^{+}-\mathrm{NO}_{3}^{-}$ & 13.5342 & 17.0 & -3.07186 & 1.96582 & -1.41191 & 0 & 0 \\
$\mathrm{H}^{+}-\mathrm{Cl}^{-}$ & 20.009 & 13.0 & -13.026 & -8.806 & 0 & 0 & 0 \\
$\mathrm{NH}_{4}^{+}-\mathrm{SO}_{4}^{2-}$ & -2.858988 & 13.0 & -0.740149 & 0.940860 & -2.587430 & 0 & 0 \\
$\mathrm{NH}_{4}^{+}-\mathrm{NO}_{3}^{-}$ & 24.7529 & 7.0 & 0.900729 & 0.379736 & -1.42646 & -29.9961 & 13.0 \\
$\mathrm{NH}_{4}^{+}-\mathrm{Cl}^{-}$ & 4.65969 & 15.0 & -0.568291 & 2.07244 & -1.25000 & 0 & 0 \\
$\mathrm{Na}^{+}-\mathrm{SO}_{4}^{2-}$ & 34.4660 & 13.0 & -3.72596 & -1.95916 & -4.86057 & 0 & 0 \\
$\mathrm{Na}^{+}-\mathrm{NO}_{3}^{-}$ & 26.9994 & 5.0 & 0.0526908 & 0.266644 & -2.30288 & -21.6050 & 13.0 \\
$\mathrm{Na}^{+}-\mathrm{Cl}^{-}$ & 19.9338 & 5.0 & -5.64608 & -3.60925 & -2.45982 & 0 & 0 \\
\hline
\end{tabular}

The short range contributions for water $w$, cation $C$ and anion $A$ are calculated with equations

$$
\begin{aligned}
\ln \gamma_{w}^{S R}= & \sum_{c} \sum_{a}\left(\frac{1}{F} E_{c} E_{a} \frac{z_{c}+z_{a}}{z_{c} z_{a}}\left(1-x_{w}\right) W_{c a}+\right. \\
& x_{c} x_{a} \frac{\left(z_{c}+z_{a}\right)^{2}}{z_{c} z_{a}}\left(1-2 x_{w}\right) U_{c a}+ \\
& \left.4 x_{c} x_{a} x_{w}\left(2-3 x_{w}\right) V_{c a}\right) \\
\ln \gamma_{C}^{S R}= & \sum_{a} \sum_{c \neq C} E_{a}\left[\frac{z_{C}}{2} E_{c} \frac{z_{c}+z_{a}}{z_{c} z_{a}} W_{c a}\right]- \\
& \sum_{a} \sum_{c}\left[x_{w} E_{c} E_{a}\left(\frac{z_{C}}{2}+\frac{1}{F}\right) \frac{z_{c}+z_{a}}{z_{c} z_{a}} W_{c a}+\right. \\
& \left.2 x_{w} x_{c} x_{a} \frac{\left(z_{c}+z_{a}\right)^{2}}{z_{c} z_{a}} U_{c a}+12 x_{w}^{2} x_{c} x_{a} V_{c a}\right]+ \\
& \sum_{a}\left[x_{w} E_{a} \frac{z_{C}+z_{a}}{z_{a}} W_{C a}+\right. \\
& x_{w} x_{a} \frac{\left(z_{C}+z_{a}\right)^{2}}{z_{C} z_{a}} U_{C a}+4 x_{w}^{2} x_{a} V_{C a}- \\
& \left.E_{a}\left(1-\frac{E_{C}}{2}\right) \frac{z_{C}+z_{a}}{z_{a}} W_{C a}\right] \\
& \left.x_{c}\right]
\end{aligned}
$$

$$
\begin{aligned}
\ln \gamma_{A}^{S R}= & \sum_{c} \sum_{a \neq A} E_{c}\left[\frac{z_{A}}{2} E_{a} \frac{z_{c}+z_{a}}{z_{c} z_{a}} W_{c a}\right]- \\
& \sum_{c} \sum_{a}\left[x_{w} E_{c} E_{a}\left(\frac{z_{A}}{2}+\frac{1}{F}\right) \frac{z_{c}+z_{a}}{z_{c} z_{a}} W_{c a}+\right. \\
& \left.2 x_{w} x_{c} x_{a} \frac{\left(z_{c}+z_{a}\right)^{2}}{z_{c} z_{a}} U_{c a}+12 x_{w}^{2} x_{c} x_{a} V_{c a}\right]+ \\
& \sum_{c}\left[x_{w} E_{c} \frac{z_{c}+z_{A}}{z_{c}} W_{c A}+\right.
\end{aligned}
$$

$$
\begin{aligned}
& x_{w} x_{c} \frac{\left(z_{c}+z_{A}\right)^{2}}{z_{c} z_{A}} U_{c A}+4 x_{w}^{2} x_{c} V_{c A}- \\
& \left.E_{c}\left(1-\frac{E_{A}}{2}\right) \frac{z_{c}+z_{A}}{z_{c}} W_{c A}\right]
\end{aligned}
$$

where lower case letters refer to any other cation and anion, $E_{c}=\frac{x_{c} z_{c}}{\sum_{c} x_{c} z_{c}}, E_{a}=\frac{x_{a} z_{a}}{\sum_{a} x_{a} z_{a}}$. Fitting parameters for the SR part are symmetric $W_{c a}, U_{c a}$ and $V_{c a}$.

These equations give ion activity coefficients in mole fraction scale, so these must be converted to molality scale with Eq. (B11). Parameters for IW part were not fitted, but these are from Clegg et al. (1992); Clegg and Brimblecombe (1995); Clegg et al. (1998a). Parameters are presented in Table 11 .

OW/OI interactions are calculated with UNIFAC. Also here, the ion activity coefficients are normalized to infinite dilution reference state and from mole fraction scale to molality scale with Eq. (B11). In the original Ming and Russell model, surface area and volume parameters for ions were the same as for water, and all ion-water and ion-ion interaction parameters were zeros. For this reason, the OW/OI contribution for water and electrolytes is zero if the organic fraction is zero. The same values were selected to our modified model. Organic-water UNIFAC parameters are the same as in the other fitted models (Tables 7 and 8). Organic-ion interaction parameters were fitted and these are given in Table 12.

\section{Appendix D: Extended UNIFAC}

The fourth model, called Extended UNIFAC, is a modification of Extended UNIQUAC (Thomsen et al., 1996) and Modified UNIFAC (Achard et al., 1994). Activity coefficients are calculated as a sum of LR and SR contributions

$$
\ln \gamma_{i}=\ln \gamma_{i}^{\mathrm{LR}}+\ln \gamma_{i}^{\mathrm{SR}}
$$


Table 12. Fitted UNIFAC organic-ion interaction parameters $a_{i j}(\mathrm{~K})$ for the Ming and Russell model. Some parameters are zeros because of lack of experimental data. Water-organic interaction parameters are in the Table 8 , and ion-ion and water-ion interaction parameters were set to zero.

\begin{tabular}{llllllllllll}
\hline $\mathrm{i}$ & $\mathrm{j}$ & $a_{i j}$ & $a_{j i}$ & $\mathrm{i}$ & $\mathrm{j}$ & $a_{i j}$ & $a_{j i}$ & $\mathrm{i}$ & $\mathrm{j}$ & $a_{i j}$ & $a_{j i}$ \\
\hline $\mathrm{CH}_{\mathrm{n}}$ & $\mathrm{H}^{+}$ & 0 & 0 & $\mathrm{OH}$ & $\mathrm{H}^{+}$ & 0 & 0 & $\mathrm{COOH}$ & $\mathrm{H}^{+}$ & 0 & 0 \\
$\mathrm{CH}_{\mathrm{n}}$ & $\mathrm{NH}_{4}^{+}$ & 10.76 & 1235 & $\mathrm{OH}$ & $\mathrm{NH}_{4}^{+}$ & -2.412 & -385.4 & $\mathrm{COOH}$ & $\mathrm{NH}_{4}^{+}$ & -18.89 & -195.8 \\
$\mathrm{CH}_{\mathrm{n}}$ & $\mathrm{Na}^{+}$ & -715.2 & -381.4 & $\mathrm{OH}$ & $\mathrm{Na}^{+}$ & -517.1 & -480.5 & $\mathrm{COOH}$ & $\mathrm{Na}^{+}$ & 2305 & -603.6 \\
$\mathrm{CH}_{\mathrm{n}}$ & $\mathrm{SO}_{4}^{2-}$ & 1085 & 9.192 & $\mathrm{OH}$ & $\mathrm{SO}_{4}^{2-}$ & -15.52 & 456.8 & $\mathrm{COOH}$ & $\mathrm{SO}_{4}^{2-}$ & -40.39 & -924.3 \\
$\mathrm{CH}_{\mathrm{n}}$ & $\mathrm{HSO}_{4}^{-}$ & 0 & 0 & $\mathrm{OH}$ & $\mathrm{HSO}_{4}^{-}$ & 0 & 0 & $\mathrm{COOH}$ & $\mathrm{HSO}_{4}^{-}$ & 0 & 0 \\
$\mathrm{CH}_{\mathrm{n}}$ & $\mathrm{NO}_{3}^{-}$ & 601.5 & -256.2 & $\mathrm{OH}$ & $\mathrm{NO}_{3}^{-}$ & -722.1 & -229.4 & $\mathrm{COOH}$ & $\mathrm{NO}_{3}^{-}$ & -122.8 & -5.668 \\
$\mathrm{CH}_{\mathrm{n}}$ & $\mathrm{Cl}^{-}$ & -790.4 & 164.2 & $\mathrm{OH}$ & $\mathrm{Cl}^{-}$ & 2814 & 738.3 & $\mathrm{COOH}$ & $\mathrm{Cl}^{-}$ & 344.2 & 5.473 \\
\hline
\end{tabular}

Table 13. Fitted UNIFAC non-electrolyte-ion and cation-anion interaction parameters $a_{i j}(\mathrm{~K})$ for the Extended UNIFAC. Some parameters are zeros because of lack of experimental data. Water-organic interaction parameters are in the Table 8 .

\begin{tabular}{|c|c|c|c|c|c|c|c|c|c|c|c|}
\hline i & j & $a_{i j}$ & $a_{j i}$ & $\mathrm{i}$ & $\mathrm{j}$ & $a_{i j}$ & $a_{j i}$ & $\mathrm{i}$ & $\mathrm{j}$ & $a_{i j}$ & $a_{j i}$ \\
\hline $\mathrm{H}_{2} \mathrm{O}$ & $\mathrm{Na}^{+}$ & -174.6 & 13.0 & $\mathrm{CH}_{\mathrm{n}}$ & $\mathrm{SO}_{4}^{2-}$ & 0.537 & -0.019 & $\mathrm{COOH}$ & $\mathrm{NO}_{3}^{-}$ & -54.38 & -161.1 \\
\hline $\mathrm{H}_{2} \mathrm{O}$ & $\mathrm{NH}_{4}^{+}$ & -2.326 & -0.581 & $\mathrm{OH}$ & $\mathrm{Na}^{+}$ & 6.235 & 4.452 & $\mathrm{COOH}$ & $\mathrm{SO}_{4}^{2-}$ & -2122 & 0.009 \\
\hline $\mathrm{H}_{2} \mathrm{O}$ & $\mathrm{H}^{+}{ }^{4}$ & -2157 & -355.6 & $\mathrm{OH}$ & $\mathrm{NH}_{4}^{+}$ & 0.968 & -277.7 & $\mathrm{Na}^{+}$ & $\mathrm{Cl}^{-}$ & -10.59 & -640.4 \\
\hline $\mathrm{H}_{2} \mathrm{O}$ & $\mathrm{Cl}^{-}$ & -7.833 & -538.6 & $\mathrm{OH}$ & $\mathrm{H}^{+}{ }^{4}$ & 0 & 0 & $\mathrm{Na}^{+}$ & $\mathrm{NO}_{3}^{-}$ & -1269 & 36.91 \\
\hline $\mathrm{H}_{2} \mathrm{O}$ & $\mathrm{NO}_{3}^{-}$ & -834.5 & -192.7 & $\mathrm{OH}$ & $\mathrm{Cl}^{-}$ & 0.018 & 2005 & $\mathrm{Na}^{+}$ & $\mathrm{SO}_{4}^{2-}$ & 0.158 & -686.1 \\
\hline $\mathrm{H}_{2} \mathrm{O}$ & $\mathrm{SO}_{4}^{3-}$ & -1983 & 0.001 & $\mathrm{OH}$ & $\mathrm{NO}_{3}^{-}$ & -3.648 & 1.714 & $\mathrm{NH}_{4}^{+}$ & $\mathrm{Cl}^{-}$ & -894.0 & 1841 \\
\hline $\mathrm{CH}_{\mathrm{n}}$ & $\mathrm{Na}^{+}$ & 2.549 & -3.737 & $\mathrm{OH}$ & $\mathrm{SO}_{4}^{2-}$ & 0.045 & -17.60 & $\mathrm{NH}_{4}^{+}$ & $\mathrm{NO}_{3}^{-}$ & -685.4 & -489.0 \\
\hline $\mathrm{CH}_{\mathrm{n}}$ & $\mathrm{NH}_{4}^{+}$ & -24.48 & 0.099 & $\mathrm{COOH}$ & $\mathrm{Na}^{+}$ & 6.684 & -0.002 & $\mathrm{NH}_{4}^{+}$ & $\mathrm{SO}_{4}^{2-}$ & 2.168 & -438.8 \\
\hline $\mathrm{CH}_{\mathrm{n}}$ & $\mathrm{H}^{+}{ }^{+}$ & 0 & 0 & $\mathrm{COOH}$ & $\mathrm{NH}_{4}^{+}$ & 16.20 & -278.1 & $\mathrm{H}^{+}{ }^{+}$ & $\mathrm{Cl}^{-}$ & -5.281 & -3.361 \\
\hline $\mathrm{CH}_{\mathrm{n}}$ & $\mathrm{Cl}^{-}$ & 5.390 & 19.54 & $\mathrm{COOH}$ & $\mathrm{H}^{+}{ }^{+}$ & 0 & 0 & $\mathrm{H}^{+}$ & $\mathrm{NO}_{3}^{-}$ & -0.001 & -391.1 \\
\hline $\mathrm{CH}_{\mathrm{n}}$ & $\mathrm{NO}_{3}^{-}$ & -1123 & 0.002 & $\mathrm{COOH}$ & $\mathrm{Cl}^{-}$ & 0.025 & 5006 & $\mathrm{H}^{+}$ & $\mathrm{SO}_{4}^{2-}$ & 143.0 & 92.51 \\
\hline
\end{tabular}

The LR part is the same as the Debye-Hückel part in Iliuta et al. (2000) version of Extended UNIQUAC, and the SR part is the UNIFAC with new functional groups for ions and organics.

The LR contribution is always zero for organics, but molality scale equations for water $(w)$ and ion $(i)$ activity coefficients from Iliuta et al. (2000) are

$$
\begin{aligned}
\ln \gamma_{w}^{\mathrm{LR}}= & \frac{2 A M_{w}}{b^{3}}\left(1+b \sqrt{I}-\frac{1}{1+b \sqrt{I}}-\right. \\
& 2 \ln (1+b \sqrt{I})) \\
\ln \gamma_{i}^{\mathrm{LR}}= & \frac{-z_{i}^{2} A \sqrt{I}}{1+b \sqrt{I}}
\end{aligned}
$$

In the Extended UNIQUAC, the constant $b$ has the value $1.50 \mathrm{~kg}^{1 / 2} \mathrm{~mol}^{-1 / 2}$ and molality scale Debye-Hückel parameter $A\left(\mathrm{~kg}^{1 / 2} \mathrm{~mol}^{-1 / 2}\right)$ is given as a function of temperature based on the temperature dependence of density and dielectric constant of pure water:

$A=1.131+1.335 \cdot 10^{-3}(T / \mathrm{K}-273.15)+$

$$
1.164 \cdot 10^{-5}(T / \mathrm{K}-273.15)^{2}
$$

This equation is valid at temperatures $273.15 \mathrm{~K}<T<383.15 \mathrm{~K}$. These constants are also used in the Extended UNIFAC.

The SR part is the same as in the three other models. Again, ion activity coefficients are normalized to infinite dilution reference state and to molality scale. Organic-water interaction parameters (Table 7), and surface and area parameters for all species (Table 8) are the same as in the other models. Ion-solvent and cation-anion interaction parameters for Extended UNIFAC are given in Table 13. Because we had only single electrolyte data, cation-cation and anion-anion interaction parameters were not fitted.

Edited by: M. Kulmala 


\section{References}

Abrams, D. S. and Prausnitz, J. M.: Statistical thermodynamics of liquid mixtures: a new expression for the excess Gibbs energy of partly or completely miscible systems, AIChE J., 21, 116-128, 1975.

Achard, C., Dussap, C. G., and Gros, J. B.: Representation of vapour-liquid equilibria in water-alcohol-electrolyte mixtures with a modified UNIFAC group-contribution method, Fluid Phase Equilibria, 98, 71-89, 1994.

Albright, J. G., Rard, J. A., Serna, S., Summers, E. E., and Yang, M. C.: Isopiestic determination of the osmotic and activity coefficients of $\mathrm{ZnSO}_{4}(\mathrm{aq})$ at $T=298.15 \mathrm{~K}$, and the standard potential of the electrochemical cell $\mathrm{ZnHg}_{\mathrm{x}}$ (two phase) $\mid \mathrm{ZnSO}_{4}$ (aq) $\mid \mathrm{PbSO}_{4}$ (s) $\mid \mathrm{PbHg}_{\mathrm{x}}$ (two phase), J. Chem. Thermodynamics., 32, 1447-1487, 2000.

Ansari, A. S. and Pandis, S. N.: Prediction of multicomponent inorganic atmospheric aerosol behavior, Atmos. Environ., 33, 745757, 1999.

Apelblat, A. and Korin, E.: The vapour pressures of saturated aqueous solutions of sodium chloride, sodium bromide, sodium nitrate, sodium nitrite, potassium iodate, and rubidium chloride at temperatures from $227 \mathrm{~K}$ to $323 \mathrm{~K}$, J. Chem. Thermodynamics., 30, 59-71, 1998a.

Apelblat, A. and Korin, E.: Vapour pressures of saturated aqueous solutions of ammonium iodide, potassium iodide, potassium nitrate, strontium chloride, lithium sulphate, sodium thiosulphate, magnesium nitrate, and uranyl nitrate from $\mathrm{T}=(278$ to 323$) \mathrm{K}$, J. Chem. Thermodynamics., 30, 459-471, 1998 b.

Apelblat, A. and Korin, E.: The vapour pressure of water over saturated solutions of sodium sulfate, calcium bromide, ferric chloride, zinc nitrate, calcium nitrate, and lithium nitrate at temperatures from $278.15 \mathrm{~K}$ to $323.15 \mathrm{~K}$, J. Chem. Thermodynamics., 34, 1621-1637, 2002.

Apelblat, A., Dov, M., Wisniak, J., and Zabicky, J.: The vapour pressure of water over saturated aqueous solutions of malic, tartaric, and citric acids, at temperatures from $288 \mathrm{~K}$ to $323 \mathrm{~K}$, J. Chem. Thermodynamics., 27, 35-41, 1995a.

Apelblat, A., Dov, M., Wisniak, J., and Zabicky, J.: Osmotic and activity coefficients of $\mathrm{HO}_{2} \mathrm{CCH}_{2} \mathrm{C}(\mathrm{OH})\left(\mathrm{CO}_{2} \mathrm{H}\right) \mathrm{CH}_{2} \mathrm{CO}_{2} \mathrm{H}$ (citric acid) in concentrated aqueous solutions at temperatures from 298.15 K to 318.15 K, J. Chem. Thermodynamics., 27, 347-353, $1995 \mathrm{~b}$

Brooks, S. D., Wise, M. E., Cushing, M., and Tolbert, M. A.: Deliquescence behavior of organic/ammonium sulfate aerosol, Geophys. Res. Lett., 29, 1917, doi:10.1029/2002GL014733, 2002.

Choi, M. Y. and Chan, C. K.: The effects of organic species on the hygroscopic behaviors of inorganic aerosols, Env. Sci. Tech., 36, 2422-2428, 2002.

Chow, J. C., Watson, J. G., Fujita, E. M., Lu, Z., Lawson, D. R., and Ashbaugh, L. L.: Temporal and spatial variations of $\mathrm{PM}_{2.5}$ and $\mathrm{PM}_{10}$ aerosol in the Southern California air quality study, Atmos. Environ., 28, 2061-2080, 1994.

Clegg, S. L. and Brimblecombe, P.: Equilibrium partial pressures and mean activity and osmotic coefficients of $0-100 \%$ nitric acid as a function of temperature, J. Phys. Chem., 94, 5369-5380, 1990.

Clegg, S. L. and Brimblecombe, P.: Application of a multicomponent thermodynamic model to activities and thermal properties of $0-40 \mathrm{~mol} \mathrm{~kg}^{-1}$ aqueous sulfuric acid from $<200$ to $328 \mathrm{~K}$,
J. Chem. Eng. Data, 40, 43-64, 1995.

Clegg, S. L., Pitzer, K. S., and Brimblecombe, P.: Thermodynamics of multicomponent, miscible, ionic solutions. 2. Mixtures including unsymmetrical electrolytes, J. Phys. Chem., 96, 9470-9479, 1992.

Clegg, S. L., Milioto, S., and Palmer, D. A.: Osmotic and activity coefficients of aqueous $\left(\mathrm{NH}_{4}\right)_{2} \mathrm{SO}_{4}$ as a function of temperature, and aqueous $\left(\mathrm{NH}_{4}\right)_{2} \mathrm{SO}_{4}-\mathrm{H}_{2} \mathrm{SO}_{4}$ mixtures at $298.15 \mathrm{~K}$ and 323.15 K, J. Chem. Eng. Data, 41, 455-467, 1996.

Clegg, S. L., Brimblecombe, P., and Wexler, A. S.: Thermodynamic model of the system $\mathrm{H}^{+}-\mathrm{NH}_{4}^{+}-\mathrm{SO}_{4}^{2-}-\mathrm{NO}_{3}^{-}-\mathrm{H}_{2} \mathrm{O}$ at tropospheric temperatures, J. Phys. Chem. A, 102, 2137-2154, 1998a.

Clegg, S. L., Brimblecombe, P., and Wexler, A. S.: Thermodynamic model of the system $\mathrm{H}^{+}-\mathrm{NH}_{4}^{+}-\mathrm{Na}^{+}-\mathrm{SO}_{4}^{2-}-\mathrm{NO}_{3}^{-}-\mathrm{Cl}^{-}-\mathrm{H}_{2} \mathrm{O}$ at 298.15 K, J. Phys. Chem. A, 102, 2155-2171, 1998 b.

Clegg, S. L., Seinfeld, J. H., and Brimblecombe, P.: Thermodynamic modelling of aqueous aerosols containing electrolytes and dissolved organic compounds, J. Aeros. Sci., 32, 713-738, 2001.

Correa, A., Comesana, J. F., and Sereno, A. M.: Measurement and prediction of water activity in electrolyte solutions by a modified ASOG group contribution method, Fluid Phase Equilibria, 129, 267-283, 1997.

Cruz, C. N. and Pandis, S. N.: Deliquescence and hygroscopic growth of mixed inorganic-organic atmospheric aerosol, Env. Sci. Tech., 34, 4313-4319, 2000.

El Guendouzi, M. and Dinane, A.: Determination of water activities, osmotic and activity coefficients in aqueous solutions using the hygrometric method, J. Chem. Thermodynamics, 32, 297$310,2000$.

El Guendouzi, M., Dinane, A., and Mounir, A.: Water activities, osmotic and activity coefficients in aqueous chloride solutions at $T=298.15 \mathrm{~K}$ by the hygrometric method, J. Chem. Thermodynamics., 33, 1059-1072, 2001.

El Guendouzi, M., Mounir, A., and Dinane, A.: Water activity, osmotic and activity coefficients of aqueous solutions of $\mathrm{Li}_{2} \mathrm{SO}_{4}, \mathrm{Na}_{2} \mathrm{SO}_{4}, \mathrm{~K}_{2} \mathrm{SO}_{4},\left(\mathrm{NH}_{4}\right)_{2} \mathrm{SO}_{4}, \mathrm{MgSO}_{4}, \mathrm{MnSO}_{4}$, $\mathrm{NiSO}_{4}, \mathrm{CuSO}_{4}$ and $\mathrm{ZnSO}_{4}$ at $298.15 \mathrm{~K}$, J. Chem. Thermodynamics, 35, 209-220, 2003.

Fowler, R. H. and Guggenheim, A. E.: Statistical thermodynamics, Cambridge University Press, 1949.

Fredenslund, A., Jones, R. L., and Prausnitz, J. M.: Groupcontribution estimation of activity coefficients in non-ideal liquid mixtures, AIChE J., 21, 1086-1098, 1975.

Greenspan, L.: Humidity fixed points of binary saturated aqueous solutions, Journal of Research of the National Bureau of Standards-A, Phys. Chem., 81A, 89-96, 1977.

Hamer, W. J. and Wu, Y.-C.: Osmotic coefficients and mean activity coefficients of uni-univalent electrolytes in water at $25^{\circ} \mathrm{C}$, J. Phys. Chem. Ref. Data, 1, 1047-1099, 1972.

Hämeri, K., Charlson, R., and Hansson, H.-C.: Hygroscopic properties of mixed ammonium sulfate and carboxylic acids particles, AIChE J., 48, 1309-1316, 2002.

Hansen, A. R. and Beyer, K. D.: Experimentally determined thermochemical properties of the malonic acid/water system: Implications for atmospheric aerosols, J. Phys. Chem. A, 108, $3457-$ 3466, 2004.

Hansen, H. K., Rasmussen, P., Fredenslund, A., Schiller, M., and Gmehling, J.: Vapor-liquid equilibria by UNIFAC groupcontribution, 5. Revision and extension, Ind. Eng. Chem. Res., 
30, 2352-2355, 1991.

Hemming, B. L. and Seinfeld, J. H.: On the Hygroscopic Behavior of Atmospheric Organic Aerosols, Ind. Eng. Chem. Res., 40, 4162-4171, 2001.

Hori, M., Ohta, S., Murao, N., and Yamagata, S.: Activation capability of water soluble organic substances as CCN, J. Atmos. Chem., 34, 419-448, 2003.

Iliuta, M. C., Thomsen, K., and Rasmussen, P.: Extended UNIQUAC model for correlation and prediction of vapour-liquid-solid equilibria in aqueous salt systems containing non-electrolytes. Part A. Methanol-water-salt systems, Chem. Eng. Sci., 55, 2673-2686, 2000.

Larsen, B. L., Rasmussen, P., and Fredenslund, A.: A modified UNIFAC group-contribution model for prediction of phase equilibria and heats of mixing, Ind. Eng. Chem. Res., 26, 2274-2286, 1987.

Levien, B. J.: A physicochemical study of aqueous citric acid solutions, J. Phys. Chem., 59, 640-644, 1955.

Li, J., Polka, H.-M., and Gmehling, J.: A $\mathrm{g}^{E}$ model for single and mixed solvent electrolyte systems: 1 . Model and results for strong electrolytes, Fluid Phase Equilibria, 94, 89-114, 1994.

Lightstone, J. M., Onasch, T. B., Imre, D., and Oatis, S.: Deliquescence, efflorescence, and water activity in ammonium nitrate and mixed ammonium nitrate/succinic acid microparticles, J. Phys. Chem. A, 104, 9337-9346, 2000.

Maffia, M. C. and Meirelles, A. J. A.: Water activity and $\mathrm{pH}$ in aqueous polycarboxylic acid systems, J. Chem. Eng. Data, 46, 582-587, 2001.

Marcolli, C., Luo, B., and Peter, T.: Mixing of the organic aerosol fractions: Liquids as the thermodynamically stable phases, J. Phys. Chem. A, 108, 2216-2224, 2004.

Ming, Y. and Russell, L. M.: Thermodynamic equilibrium of organic-electrolyte mixtures in aerosol particles, AIChE J., 48, 1331-1348, 2002.

Nelder, J. A. and Mead, R.: A simplex method for function minimization, Computer J., 7, 308-313, 1965.

Novakov, T. and Penner, J. E.: Large contribution of organic aerosols to cloud-condensation-nuclei concentrations, Nature, 365, 823-826, 1993.

Peng, C., Chan, M. N., and Chan, C. K.: The hygroscopic properties of dicarboxylic and multifunctional acids: Measurements and UNIFAC predictions, Env. Sci. Tech., 35, 4495-4501, 2001.

Pinho, S. P. and Macedo, E. A.: Experimental measurement and modelling of $\mathrm{KBr}$ solubility in water, methanol, ethanol, and its binary mixed solvents at different temperatures, J. Chem. Thermodynamics, 34, 337-360, 2002.
Pitzer, K. S.: Activity Coefficients in Electrolyte Solutions, CRC Press, 2 edn., 1991.

Prenni, A. J., DeMott, P. J., and Kreidenweis, S. M.: Water uptake of internally mixed particles containing ammonium sulfate and dicarboxylic acids, Atmos. Environ., 37, 4243-4251, 2003.

Rard, J. A. and Clegg, S. L.: Critical evaluation of the thermodynamic properties of aqueous calcium chloride. 1 . Osmotic and activity coefficients of $0-10.77 \mathrm{~mol} \cdot \mathrm{kg}^{-1}$ aqueous calcium chloride solutions at $298.15 \mathrm{~K}$ and correlation with extended Pitzer ion-interaction models, J. Chem. Eng. Data, 42, 819-849, 1997.

Robinson, R. A. and Stokes, R. H.: Electrolyte Solutions, Butterworths Scientific Publications, 2 edn., 1959.

Saxena, P. and Hildemann, L. M.: Water-soluble organics in atmospheric particles: a critical review of the literature and application of thermodynamics to identify candidate compounds, J. Atmos. Chem., 24, 57-109, 1996.

Schunk, A. and Maurer, G.: Activity of water in aqueous solutions of sodium citrate and in aqueous solutions of (an inorganic salt and citric acid) at 298.15 K, J. Chem. Eng. Data, 49, 944-949, 2004.

Seinfeld, J. H. and Pandis, S. N.: Atmospheric chemistry and physics: from air pollution to climate change, Wiley, New York, 1998.

Srinivasakannan, C., Vasanthakumar, R., and Rao, P. G.: A study on crystallization of oxalic acid in batch cooling crystallizer, Chem. Biochem. Eng. Q., 16, 125-129, 2002.

Stokes, R. H. and Robinson, R. A.: Interactions in aqueous nonelectrolyte solutions. I. Solute-Solvent Equilibria, J. Phys. Chem., 70, 2126-2131, 1966.

Thomsen, K. and Rasmussen, P.: Modeling of vapor-liquid-solid equilibrium in gas-aqueous electrolyte systems, Chem. Eng. Sci., 54, 1787-1802, 1999.

Thomsen, K., Rasmussen, P., and Gani, R.: Correlation and prediction of thermal properties and phase behaviour for a class of aqueous electrolyte systems, Chem. Eng. Sci., 51, 3675-3683, 1996.

Topping, D. O., McFiggans, G. B., and Coe, H.: A curved multicomponent aerosol hygroscopicity model framework: 2 - Including organics, Atmos. Chem. Phys., 5, 1223-1242, 2005,

SRef-ID: 1680-7324/acp/2005-5-1223.

Weast, R. C.: CRC Handbook of Chemistry and Physics, CRC Press, Boca Raton Florida, 1987.

Yan, W., Topphoff, M., Rose, C., and Gmehling, J.: Prediction of vapor-liquid equilibria in mixed-solvent electrolyte systems using the group contribution concept, Fluid Phase Equilibria, 162, 97-113, 1999. 